\title{
A SOCIAL REPRESENTATIONS APPROACH TO THE COMPARISON OF THREE TEXTUAL CORPORA USING ALCESTE
}

\author{
by \\ Nicholas C. Allum \\ A dissertation submitted in partial fulfillment \\ of the requirements for the degree of \\ MSc Social Research Methods (Philosophy) \\ London School of Economics and Political \\ Science
}

1998 


\begin{abstract}
Three corpora of textual data on biotechnology from a range of sources (newspaper articles, focus group transcriptions and responses to an openended question from a survey) were analysed using the computer program ALCESTE. A comparison of characteristic classes of words from each corpus was made in order to identify the stable components in the public's perception of biotechnology seen in differing communicative contexts. The results indicate that at least three distinct representations are present in all the spheres of discourse explored. The steps required to prepare text and carry out analyses using the program are described, and an assessment is made of the method and its prospects as a research tool.
\end{abstract}




\section{Contents}

INTRODUCTION

$\begin{array}{lr}\text { ALCESTE }^{T M} & 3\end{array}$

ALCESTE: conceptual roots 4

$\begin{array}{lr}\text { ALCESTE and statistical methodology } & 5\end{array}$

Biotechnology and the British public - myths, metaphors and representations $\quad 7$

$\begin{array}{ll}\text { METHOD } & 10\end{array}$

Datasets $\quad 10$

$\begin{array}{ll}\text { Focus group interviews } & 10\end{array}$

Open question responses 11

$\begin{array}{ll}\text { News media } & 12\end{array}$

$\begin{array}{ll}\text { Text preparation } & 13\end{array}$

News media $\quad 15$

Focus groups $\quad 15$

$\begin{array}{ll}\text { Open questions } & 16\end{array}$

$\begin{array}{ll}\text { Content-specific preparation } & 17\end{array}$

$\begin{array}{ll}\text { Main analysis } & 17\end{array}$

$\begin{array}{ll}\text { Supplementary analysis - open questions } & 18\end{array}$

$\begin{array}{ll}\text { RESULTS } & 20\end{array}$

Lexical classes $\quad 21$

News media $\quad 21$

$\begin{array}{ll}\text { Focus groups } & 27\end{array}$

Open question responses 33

Comparison of classical content analysis and ALCESTE classification 39

$\begin{array}{ll}\text { DISCUSSION } & 41\end{array}$

Biotechnology and social representations $\quad 41$

ALCESTE and methodology $\quad 44$

$\begin{array}{ll}\text { REFERENCES } & 47\end{array}$

$\begin{array}{ll}\text { APPENDIX } & 49\end{array}$ 


\section{$\underline{\text { List of Tables }}$}

Focus groups: demographics and newspaper readership $\quad 11$

Number of articles per newspaper $\quad 12$

Alceste analyses: basic information $\quad 20$

News media: characteristic words ordered by strength of association $\quad 24$

Focus groups: characteristic words ordered by strength of association 29

Open question responses: characteristic words ordered by strength of association35

\section{List of Figures}

News media: correspondence analysis of characteristic words 25

News media: correspondence analysis of lexical classes and publications $\quad 26$

Focus groups: correspondence analysis of characteristic words 31

Focus groups: correspondence analysis of lexical classes and demographics $\quad 32$

Open question responses: correspondence analysis of characteristic words $\quad 37$

Open question responses: correspondence analysis of lexical classes $\quad 38$

Open question responses: correspondence analysis of lexical classes and classical content analysis coding (valuation of biotechnology) 40

Figurative nucleus 


\section{Introduction}

Since the arrival of the electronic computer during the 1940s, social researchers interested in analysing and interpreting texts have attempted to make use of the everincreasing processing power which has become available to them. During the 1960s, with the appearance of mainframe and mini computers in most universities, the possibility of being able to automate entirely the, up until then, manual task of coding and analysing text came to be seen as a kind of 'holy grail' for some social scientists. Markoff et al (Markoff, Shapiro \& Weitman, 1974) called this tendency the 'Golemic Approach ${ }^{, 1}$ to documentary analysis. The reasons for wanting a machine to do the work that had previously occupied hundreds of hours of human coding time were not just part of a 'space-age' 1960s zeitgeist which saw new technology as an unreservedly liberating and progressive force. There were, and still remain, good methodological reasons for considering the possibility of dispensing with the manual coding of text. Content analysis has been attractive to social scientists not least because it allows for the quantification of manifest features of text. But this quantitative 'hard edge' is lost if the categories and codes used as variables are compromised through human error: firstly in their specification, and, secondly, in their measurement. Automation of these tasks by computers would, so the story goes, substantially reduce problems of reliability and validity inherent in content analysis as practised by less than perfectly reliable humans.

In fact, the vastly more powerful computers of today have not so far allowed us to dispense with the need for user-intervention in the coding of data deriving from written texts, or, for that matter, any other forms of 'text' such as movies, TV advertisements, or documentary film. Part of the reason for this is, no doubt, that social researchers are not, in general, computer scientists. Cutting-edge developments in software design are not the main focus of social researchers' work, and are, as a result, less likely to be utilised for social research purposes until they reach the mainstream (Bechtel, 1997; Evans, 1996). But even using the latest artificial intelligence and neural network

\footnotetext{
${ }^{1}$ The Golem was a mythical automaton that could carry out any human task. It would receive its instructions by having a piece of paper placed in its mouth, after which its owner could go to bed knowing that all his work would be done by morning.
} 
programming techniques, we are even now a long way from developing software which can extract meanings from text with anything like the facility of a human coder. This is, perhaps, not surprising in the light of theoretical debates concerning semantics in the fields of linguistics and philosophy. Wittgenstein famously argued that it was not possible to alight on a precise definition of a word's meaning by stating sets of necessary and sufficient conditions for its membership of the class for which it stands (Garnham, 1985; Wittgenstein, 1953). His example was that of the word game. There is, according to Wittgenstein, no set of characteristics common to all games. Instead there are overlapping sets of similarities between different activities, all of which we describe as games. For example, a game may involve winning or losing, or it may involve play-acting, or neither of these. We would, though, reasonably expect to be able to say whether something was a game or not. There are, as Wittgenstein would have it, family resemblances between what we call games; but these cannot necessarily be operationalised as definitions. And there may be, in consequence, no way of programming a computer with an algorithm which can determine meanings in context from a set of axioms or definitions given a priori.

So much for the Golem. But for computers to be a useful tool for textual analysis they need not replace human coders altogether. This fairly obvious assertion is made all the more compelling if we see content analysis not as existing in a 'methodological ghetto' but as one technique, relatively undifferentiated from many others, for understanding and explaining interesting social and psychological phenomena. As Galtung has remarked, 'the most important thing about content analysis is that there is nothing particular about it at all' (Galtung, 1967:67). If we consider Krippendorff's definition of content analysis, '.... a research technique for making replicable and valid inferences from data to their context' (Krippendorff, 1980:21) there is nothing to prevent us applying it equally well to, for instance, survey work, or to psychometrics, or economics. In fact Krippendorff's definition is nothing other than a specific attempt at defining a generalised 'scientific method'. The aporia resulting from so doing have provided philosophers of science with gainful employment for two centuries since Kant. Content analysis is no more or less implicated in these debates than any other technique of social science. 
The view which follows from this is that content analysis (whether automated or handcoded) should be seen as part of a battery of techniques which may or may not be useful to the social scientist in any given research situation. The question of which techniques to use in a particular context remains an empirical one, at least to some degree. Accordingly, the most useful purpose of this paper will be to introduce a particular method for analysing textual data using a new (at least outside of France) computer application, and to explore its strengths and weaknesses as a research tool. This will be carried out using a corpus of textual data gathered previously for a specific social research purpose - and which has already been analysed using various other research methodologies.

\section{ALCESTETM}

ALCESTE is a software application which can run on PCs or Apple Macintosh computers. It was originally developed by Max Reinert during the 1980s, and the latest PC version (4) runs under Microsoft Windows 95. This is the version under discussion in this paper. Whilst there is now an English users' manual, all the onscreen documentation, menus and dialogues currently remain in French.

According to the author, ALCESTE is a 'tool for determining the main word distribution patterns within a text or discourse. These are word sets which can be considered as "rude facts" on which to start building an interpretation' (Reinert, 1998:1). ALCESTE does not use extensive dictionaries of semantic categories for its primary analysis. Rather it relies on the distribution pattern of words within the corpus:

The objective is to obtain a primary statistical classification of the "simple statements" of the studied corpus in function of the way words are distributed within these "statements" - in order to reveal the most characteristic words.

After preparing the text in a pre-specified format, the user can run an analysis, using standard or default parameter settings 'so that the form of the output doesn't depend on the researcher's prejudices concerning the content' (ibid.). This is an important 
aspect of the program. Since a simple analysis can be carried out with little or no intervention from the user, a de facto procedure for replicating research has been established.

The corpus of text to be analysed can, according to Reinert, take the form of collections of articles, open question survey responses, interview and focus group transcripts, dream narratives and literary texts. In fact it was in the Humanities departments of universities in France that ALCESTE was first used, to analyse novels, plays and poems see (Reinert, 1987).

A precondition which must be met by the corpus to be analysed is that of relative homogeneity. The entire text should be consistent in its conditions of production and in the focus of the themes present. This means that one should not expect useful results from analysing a corpus that is a mixture of, say, focus group transcriptions and newspaper articles. Nor should one attempt to analyse, for instance, a set of depth interview transcriptions unless they all address the same topics. A further requirement of the program is that the corpus should be at least 10,000 words in length. The word classifications derived from samples of text much shorter than this are less likely to yield stable or substantively interesting results.

\section{ALCESTE: conceptual roots}

Reinert's theoretical rationale for the ALCESTE program comes, at least in part, from the idea of 'free association' and dream analysis in the Freudian and Jungian psychoanalytic traditions. " In Freudian psychoanalysis, a subject who is asked to speak freely about anything which enters their head may reveal the presence of unconscious thoughts and intentions that are submerged during normal conversation. Freud referred to the idea of the manifest and latent contents of speech, and suggested that 'intentions can find expression in a speaker of which he himself knows nothing but which I am able to infer from circumstantial evidence' (Freud, 1917:92). The latent (unconscious) part of the subject's dialogue can be inferred from its manifest content. Jung, later, went further than this. He found that part of the unconscious, the

\footnotetext{
* Private correspondence
} 
collective unconscious, contains elements akin to the themes found in myths, legends and folk tales, that are shared by everybody within a given cultural milieu (Bertine, 1967). Thus the method of free association could provide a deeper understanding of humans as social, cultural beings. The usefulness of analysing word associations, or co-occurrences, within a corpus of text - which is essentially what ALCESTE does - is predicated on the above notions. The semantic significance of the text is ignored (it is, in any case, as we have seen, beyond the capabilities of current computer technology) and the significant indications of latent meaning can be inferred by the researcher via the examination of the characteristic classes of words which form the primary output of the program.

There is, of course, no reason why the researcher need only look for latent meanings in the text. Part of the alleged strength of computer-assisted methods of analysis is that they allow a previously unmanageable quantity of material to be analysed quickly for recurring themes or topics. And clearly one might expect to interpret results differently according to the way in which texts have been produced in the first place. For instance one might not be so interested in interpreting the latent content of broadsheet newspaper articles so much as the manifest focus of the stories and their salience for the public. Analysis of open question survey material gained by an explicit free association method, though, may warrant an interpretation based much more on the attempt to discover latent dimensions in subjects' responses. It remains an empirical matter how important these distinctions might be as far as the practical use of the ALCESTE program is concerned.

\section{ALCESTE and statistical methodology}

ALCESTE utilises correspondence analysis to produce graphical and numerical output to aid interpretation of the corpus. Correspondence analysis is more a geometric technique than a statistical one. It allows for a graphical representation in a low-dimensional space (usually two dimensions) of categorical data of the type normally examined by means of a contingency table. Each row (or column) in a contingency table typically includes within-row or within-column percentages in each cell. In correspondence analysis these percentages are used to construct a profile for each row or column. These profiles are used as vectors to describe co-ordinates in an 
$\mathrm{n}$-dimensional space where $\mathrm{n}$ is the number of categories in the row or column variable which makes up the profile. Distances between each profile and the marginal average are calculated using the ${ }_{-}^{2}$ statistic. The vector points, which are also weighted, are finally projected onto a two dimensional plane which can be more easily interpreted. For a comprehensive review of the technique see Greenacre \& Blasius (1994).

Correspondence analysis has been historically associated with a specifically French tradition of research and has an underlying philosophical foundation which has not always found favour with social scientists working within an Anglo-Saxon research setting (van Meter, Schiltz, Cibois \& Mounier, 1996). Formal significance testing, as found in techniques like multiple regression, is sometimes downplayed in the former tradition as an irrelevance that has more rhetorical than scientific utility. According to French sociologist Benzécri, there is an implicit idealism in much social research which threatens its claim to scientific objectivity. Benzécri, during the early 1970s, felt able to propose a solution in the form of an alternative statistical procedure, correspondence analysis, aided by the electronic computer. Together these devices 'can allow us to substitute in place of common sense qualitative notions, statistically defined quantities in such a manner that the final construction, founded upon an ample factual basis, will be independent from arbitrary constructions due to a priori ideas' (Benzécri, 1973). Benzécri's position is an extreme one - he wishes to see the factors, once extracted, as the 'essence' of the reality under observation, even to the extent of forbidding a subsequent return to the original data. Despite the extremity of this philosophical view, correspondence analysis is the mainstream method of choice for the analysis of large scale multivariate data in France. Probably the most famous piece of work to use the technique was Bourdieu's La Distinction (Bourdieu, 1979) which mapped the associations of tastes and lifestyles with different social positions in France. French social survey data are routinely split into categorical groupings in order to facilitate correspondence analysis. An illustrative example, for the interested reader, is provided by a study in which a secondary analysis using this method was carried out on British social survey data (Schiltz, 1990). Correspondence analyses of textual data, closely related to the ALCESTE method, are also becoming increasingly widespread outside of France; see e.g. (Giegler \& Klein, 1994; Wagner, 1997). 
Correspondence analysis is well suited to describing and exploring data; it is less well suited to hypothesis-testing, and involves no inferential statistics (which is one reason why it has been slow to make an impact in the Anglo-Saxon tradition of research). Benzécri's maxim that 'the model must follow the data, not the reverse' is implicitly realised in the design of ALCESTE where the principal aim is, as we have seen, to uncover the latent structure of associations present within a large volume of text. Thus it is correct to see it as logically developing out of the generalised research paradigm briefly described so far. But despite Benzécri's original exhortation to treat the factors extracted by correspondence analysis as almost 'sacred essences', the technique is, nevertheless, increasingly being used as part of a multi-method approach by both French and Anglo-Saxon researchers (van Meter et al., 1996).

Having introduced the basic characteristics and philosophy behind the design of the ALCESTE program, we can now see how it can be applied to a substantive topic of interest. It is intended that the observations made during the course of the analysis may address both the methodological questions surrounding the technique itself, as well as providing some interesting insights into our chosen research area.

\section{Biotechnology and the British public - myths, metaphors and representations}

The genesis of modern biotechnology can be traced to Crick and Watson's discovery, at Cambridge in 1953, of the 'double helix' structure of DNA. Recombinant DNA technology or 'genetic engineering' was introduced during the 1970s. During the 1990s, 'biotechnology' has seemingly become the collective term which describes all forms of science and technology which flow from Crick and Watson's original work.

Recently, high profile news stories such as that of 'Dolly' the cloned sheep have increased the general public's exposure to biotechnology and have raised the temperature of public and private debate. Despite the inherent difficulty for lay people in the understanding of complex scientific issues, scientific knowledge does, nevertheless, become diffused in a 'popular' form. Complex and unfamiliar ideas are transformed and simplified into a sort of 'folk knowledge' (Wagner, 1995). The 
transformation of complex and unfamiliar concepts into such 'folk knowledge' is, according to Moscovici (Moscovici, 1984; 1988), a ubiquitous social phenomenon, and is central to his theory of social representations. This theory provides a highly suitable framework for the study of the public understanding of science. It contrasts with, for example, the 'deficit model', where the focus is on lay understanding as misunderstanding, and the underlying implication is that the scientific establishment needs to more effectively control mass media output in order to make good the knowledge gap (Bauer \& Gaskell, 1998). Social representations theory, on the other hand, sees the transformation of scientific knowledge into the realm of widely-shared beliefs, myths and images as a process that requires investigation if one is interested in explaining the dynamic nature of social reality. Jodelet's definition helps make this clear:

the concept of social representation indicates a specific form of knowledge, i.e. common-sense knowledge, the contents of which reveal the operation of processes that are generative and that [serve] distinct social purposes... Social representations are practical and communicable ways of thinking that are oriented towards an understanding and mastery of the environment (both social and material...)

(Denise Jodelet, translated in Farr (1990))

In regard to the present study, the task, then, is to explore the dimensions of 'commonsense' knowledge in relation to biotechnology. In order to make sense of the results of our investigation in terms of our chosen theoretical framework it will be useful to indicate a few key concepts before proceeding to the empirical part of the paper. For much more comprehensive treatments of these concepts and the theory of social representations in general see for example (Doise, Clemence \& Lorenzi-Cioldi, 1993; Farr, 1987; Moscovici, 1984; Moscovici, 1988; Pereira de Sa, 1996; Purkhardt, 1993; Rouquette, 1996). For a critique see (Jahoda, 1988).

'The purpose of all social representations is to make something unfamiliar, or unfamiliarity itself, familiar' (Moscovici, 1984:24). What is asserted here is that 
events, objects and ideas are always perceived in relation to previous encounters. The influence of memory outweighs that of deduction; images prevail over 'reality'. For instance, Moscovici found that some people anchored the unfamiliar concept of psychoanalysis in their understanding of 'confession'. They came to ground their understanding of the technique of 'free association' in the rules of confession (op. cit., p26). Anchoring can therefore be understood as a process of categorisation, where unfamiliar things are conciliated within a paradigm already stored in memory. In the context of the present study one might therefore expect to find biotechnology anchored in an already familiar set of ideas and images for the lay public.

When an unfamiliar idea becomes anchored within a familiar paradigm, the idea still requires a concrete image, a material form that operationalises it as something capable of being communicated:

to objectify is to discover the iconic quality of an imprecise idea or being, to reproduce a concept as an image...We have only to compare God to a father and what was invisible instantly becomes visible in our minds as a person to whom we can respond as such

(op. cit., p38).

The extent to which some objectifications are reproduced and become widely shared, whereas others are not, and the mechanism by which this occurs, could be seen as an 'epidemiology' of representations (Sperber, 1985; 1990). A particular representation becomes epidemic or endemic according to the lived experiences of different social groups. Social representations are dynamic. They do not remain constant but are continually renegotiated and transformed. In regard to the present investigation we should keep in mind the 'snapshot' nature of the objectifications, metaphors and images that may be found at one particular point in time. A representation exists contingent on the degree to which it is 'good to think with' (Wagner, 1995). The icons that make up what Moscovici (1984) describes as a representation's figurative nucleus are therefore likely to be present only while they fulfil a useful function for the social group(s) in question. 
Empirical research has attested to the dynamic, transformational nature of social representations. In addition to this they are both consensual and marked by interindividual differences (Pereira de Sa, 1996). The central nucleus theory, first proposed by Abric in 1976 (Abric, 1993), explains these inconsistencies by positing the existence of two systems: a core and a periphery. The core is composed of a small number of elements responsible for the stability and consensuality of the representation. It is grounded in the collective memory of a social group and is relatively insensitive to social context (Pereira de Sa, 1996). The periphery is composed of auxiliary elements which are sensitive to social context and allow for heterogeneity within a group whilst leaving the overall meaning of the representation unaltered. The theory has heuristic value for empirical research when we observe a range of images associated with a single concept. The task is then to differentiate between core and peripheral elements, and to see how this structure might vary according to objective criteria, e.g. sociodemographic characteristics or other natural social segmentations. In the present context we are interested to see whether the ALCESTE analyses allow us to hypothesise what might be differentiated as central and peripheral elements of representations of biotechnology, and to see whether this holds for all of the data-types investigated.

\section{Method}

\section{Datasets}

Three separate sets of textual data were used for the analysis. They consisted of a corpus of newspaper articles, transcriptions of five focus group interviews, and a set of approximately 800 'open' responses from a questionnaire survey. The latter two datasets were collected as part of a European Concerted Action research project, Biotechnology and the European Public. ${ }^{2}$

\section{Focus group interviews}

Five sessions were conducted in London and Leeds during the spring of 1996. The topic under discussion was biotechnology, also introduced as 'genetics' and 'DNA'.

\footnotetext{
${ }^{2}$ Coordinated at the London School of Economics and the Science Museum by Dr Martin Bauer, Prof John Durant and Dr George Gaskell.
} 
Overall, the groups were selected so as to cover a range of socio-demographic categories - with the profile of each particular group being relatively homogenous. These data are summarised in table 1 .

table 1

Focus groups: demographics and newspaper readership

\begin{tabular}{|c|c|c|c|c|}
\hline 1 & 2 & 3 & 4 & 5 \\
\hline $\begin{array}{l}\text { Leeds, } \\
\text { Christians, } \\
\text { A/B 35-50. }\end{array}$ & $\begin{array}{l}\text { Putney, Male, } \\
24-35, \\
\text { Interested in } \\
\text { the } \\
\text { environment }\end{array}$ & $\begin{array}{l}\text { Leeds, } A B, \\
\text { Jewish, } 35-50 \text {. }\end{array}$ & $\begin{array}{l}\text { Putney, Mixed, } \\
\text { 18-25, } \\
\text { Environmentall } \\
\text { y Aware }\end{array}$ & $\begin{array}{l}\text { Leeds, } 1 / \text { C2, } \\
\text { Female, } 24-35\end{array}$ \\
\hline $\begin{array}{l}\text { Independent, } \\
\text { The Yorkshire } \\
\text { Evening Post, } \\
\text { The Telegraph } \\
\text { The Sunday } \\
\text { Times, The } \\
\text { Times } \\
\text { Educational } \\
\text { Supplement, } \\
\text { The Guardian, } \\
\text { The Observer }\end{array}$ & $\begin{array}{l}\text { Guardian, The } \\
\text { Observer, } \\
\text { Standard, } \\
\text { Financial } \\
\text { Times }\end{array}$ & $\begin{array}{l}\text { Times, Mail on } \\
\text { Sunday, } \\
\text { Independent, } \\
\text { Standard, } \\
\text { Jewish } \\
\text { Chronicle }\end{array}$ & $\begin{array}{l}\text { Express, } \\
\text { Guardian, } \\
\text { Standard, Sun, } \\
\text { Mail, } \\
\text { Telegraph Star }\end{array}$ & $\begin{array}{l}\text { The Mail, The } \\
\text { Times, The } \\
\text { Telegraph, The } \\
\text { Independent, } \\
\text { The Observer, } \\
\text { Yorkshire } \\
\text { Evening Post, } \\
\text { Express, } \\
\text { Mirror News of } \\
\text { the World }\end{array}$ \\
\hline
\end{tabular}

\section{Open question responses}

These data originate from the Eurobarometer on Biotechnology (46.1), conducted during October and November 1996. The survey, which was conducted in each European Union country, was based on a multi-stage random sampling methodology. It provides a representative sample of individuals aged 15 and over $(n=16,246)$. Only the British data were used in the present analysis $(n=1,074)$. The survey was conducted via face to face interview. Question 7 was asked in the following way:

You've indicated to what degree you think various new technologies will change the way we live. Now, I would like to ask you what comes to mind when you think about modern biotechnology in a broad sense, that is including genetic engineering.

The responses were written down verbatim, and respondents prompted by the interviewer after each reply with the words 'anything else?'. Each case therefore consists of one or several words or phrases, or is coded $d / k$ for respondents who didn't 
answer. Eliminating the $d / k$ responses left 973 valid cases for analysis using ALCESTE.

\section{News media}

76 articles were collected using the online information service FT-Profile.

table 2

Number of articles per newspaper

\begin{tabular}{|l|l|l|}
\hline Newspaper & $\begin{array}{l}\text { Sampling } \\
\text { period }\end{array}$ & $\begin{array}{l}\text { Number of } \\
\text { articles }\end{array}$ \\
\hline Daily Mail & Aug-Sep & 6 \\
\hline Daily Telegraph & Aug-Sep & 4 \\
\hline Guardian & Aug-Sep & 5 \\
\hline Independent & Aug-Sep & 17 \\
\hline Independent on Sunday & Aug-Sep & 1 \\
\hline Mirror (inc. Sunday Mirror) & Aug-Nov & 16 \\
\hline Standard & Aug-Nov & 5 \\
\hline Sunday Telegraph & Aug-Sep & 1 \\
\hline Sunday Times & Aug-Sep & 9 \\
\hline Times & Aug-Sep & 12 \\
\hline TOTAL & & $\mathbf{7 6}$ \\
\hline
\end{tabular}

The search was restricted to August and September 1996 for all papers except for the Standard and the Mirror, for which the search was extended to the end of November 1996. This period was chosen as it coincided with the fielding of the Eurobarometer survey. The search period was extended for the Mirror and the Standard in order to increase the representation of the tabloid press in the corpus. The search string used was GENETIC*, DNA; the string BIOTECH* was not used because of the high number of articles in the financial pages that relate to market information in the 'biotech' industries, and it was found that, when running preliminary searches, 
GENETIC* or DNA always appeared alongside BIOTECH* whenever the article qualified for inclusion into the corpus. The final 76 articles were chosen on the basis that their main focus or a significant side issue was biotechnology.

It must be emphasised that the sampling frame used for the gathering of articles was not intended to be probabilistic or statistically representative. The rationale was simply to have a spread of material from newspapers that were cited as read by the focus group interviewees. And of these, only those that were available on FT-Profile were included.

\section{Text preparation}

The ALCESTE program is able to run an analysis with very little user intervention; but in order to be able to do this the text needs first to be carefully prepared. In the present case, the datasets were prepared using a common procedure, with additional modifications that were dependent on the unique characteristics of each type.

The common procedure for preparing texts for ALCESTE consists in the following steps:

1) The text needs to be saved as an ASCII file, with line breaks. This is easily achieved from within any word-processing program (the one used here was Microsoft Word 97).

2) Capital letters at the beginning of a word are automatically changed to lower case by ALCESTE. Words which are all in upper case remain so, but are not included in the main analysis. It is necessary to search for words such as these in the document and replace them with lower case letters if they are required to be analysed. For example, the acronym 'DNA' appeared many times in each corpus. This was replaced (using the search and replace function on Word 97) with 'dna'.

3) Certain symbols are used as tags by ALCESTE. These are the asterisk (*) and dollar sign (\$). Since they have special functions, they should be removed from the main text, or replaced with another symbol or word. FT-Profile output does not include currency symbols (or asterisks), using instead the word for the currency, e.g. 'dollar' for ' $\$$ ', but other text sources may include them. 
4) Apostrophes have an important function in English which is, of course, different to that in French usage; consequently they need to be handled carefully in ALCESTE. Apostrophes should be replaced by underscores (_) in order for ALCESTE to recognise words like that's as a single word, and not two (i.e. that and $s$ ).

Unfortunately, the apostrophe is isomorphic with the inverted comma for most word processing programs. This means that one needs to search for strings where the apostrophe is not preceded or succeeded by a space - in order to distinguish it from the usage of an inverted comma as a speech marker - and replace these with underscores. Then, when only inverted commas remain in the text they can be safely deleted, or replaced with spaces.

5) Tagging the corpus is necessary to a greater or lesser degree depending on the type of text involved. ALCESTE uses a hierarchy of 'context units' on which it bases its analysis. Certain types of these units can be defined by the user by tagging the text accordingly. Additionally, it is possible to include 'passive variables' associated with different text units. The different options for tagging are described in the next section, followed by the specific ways in which the datasets in the study were actually tagged.

ALCESTE operates with two main types of contextual unit, both of which can be defined by the user. An Initial Context Unit (ICU) represents a pre-existing division of the text and has to be specified. For example, if a book were to be analysed, one might want to define each chapter as an ICU. An Elementary Context Unit (ECU) is a unit of text within which ALCESTE calculates the frequency of word co-occurrences. The program automatically decides on the appropriate length for each ECU and partitions the corpus accordingly. The process is driven by the punctuation in the text. A hierarchy of symbols such as commas, full-stops, semi-colons, and, finally, the dollar sign allow ALCESTE to determine the correct length for each ECU by inspecting the natural flow of the text - as evidenced by the punctuation. The dollar sign overrides all other symbols in closing an ECU. This feature can be used to separate portions of text within the corpus that need to be analysed separately in order to make substantive sense. 
'Passive' variables can be attached to ICUs by following the ICU marker (****) with one or more 'mots étoilé'. They are 'passive' because they do not contribute to either the calculation of the lexical classes or to the factors in the correspondence analysis. So, for example, when analysing a book, each chapter might be tagged as follows:

*****chapter_name

These variables or indicators appear in the factor space from the ALCESTE correspondence analysis along with the analysed words. This enables a visual representation to be made of the associations between certain words and the variables defined by the 'mots étoilé'. In the above example, using the chapter names as a 'passive' variable allows the researcher to see what words and/or lexical classes are associated with each chapter. The tagging used on each of the three datasets on biotechnology is explained below.

\section{News media}

Each article was tagged as an ICU. Additionally the title of the newspaper was included as a passive variable. Each article was terminated by a '\$' to prevent ECUs from overlapping articles. Thus each article appears in the following form:

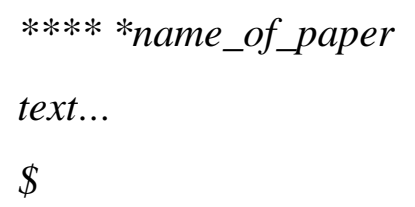

\section{Focus groups}

Each of the five groups were tagged as separate ICUs. Passive variables were added corresponding to some socio-demographic characteristics of the groups, as well as the location of the session. Two further decisions were taken in respect of the tagging. Firstly it was decided to remove the moderators' dialogue from the transcription, as it was only the respondents' dialogue that was of interest. The characteristic words used by the moderators were the same in every session, and this would influence the derivation of the lexical classes and de-emphasise the contribution of respondents' 
vocabulary. The second decision was taken on theoretical grounds. One of the reasons for using a focus group interview is that the function of an interviewer is, to some extent, fulfilled by the dynamic interaction amongst all participants. It produces 'emic' data, that is to say data that are produced 'colloquially', and that are not excessively influenced by the outlook of the researcher (Stewart \& Shamdasani, 1990). It was decided not to delimit the focus group transcriptions by keeping each participant's dialogue separate but rather to allow ALCESTE to treat each of the five groups as single ICUs. This meant that some overlapping of different participants' dialogue was likely to occur within the analysis; it is concordant with the idea that focus groups produce information that is 'more than the sum of its parts' - a valid representation of the ideas of the group as a whole. An example of the tagging used is shown below:

$* * * *$ Leeds $*$ C1C2 *Female *24_35

All dialogue (except moderator)... $\$$

(Variables shown here are for location, social class, sex and age group.)

\section{Open questions}

The preparation for the open question responses was slightly more complicated than the previous two examples. Here it was required that the response of each individual in the Eurobarometer survey could be identified with the correct case number in the original data file. As an alternative to using the four asterisks to denote the beginning of an ICU, ALCESTE interprets a string of digits at the start of a line as a new ICU with the digits forming the identification number. A text file was created by exporting cases from the Eurobarometer data using SPSS. Two variables were exported - the 'string' variable, holding the responses, and the interview number, as identification. Both were exported into an ASCII text file. Each response had a dollar sign added at the end to separate it from the next. After cleaning and preparing the text using the common procedure noted above the data appeared as in the following example: 


\section{Science fiction films}

Bad sides of it - dabbling with nature

$\$$

0471 It_s a good thing

$\$$

\section{Content-specific preparation}

Having carried out the preparation described, some preliminary analyses were run in order to check for errors in preparation and also to see if further changes were needed in relation to specific words in the texts. ALCESTE employs a technique known as 'lemmatisation' in dealing with texts. This means that textual forms (words) are, where possible, reduced to their root form to reflect their semantic similarity. Thus for example the words 'eat', 'eaten', 'eating', 'eats' are all reduced to 'eat+'. However, ALCESTE does not recognise all reduced forms; for instance the form 'genetically' was not reduced to 'genetic+', although 'genetics' was. The way around this problem was to run a preliminary analysis, examine the dictionary of significant words in the output and to search the original text for occurrences of words which were not correctly lemmatised. These were then replaced by the reduced form. In the case of the above example, all occurrences of 'genetically' were replaced with 'genetic'. It is particularly important to make sure that highly significant words are treated in this way in order to ensure that the final analysis is not confounded by the attribution of spurious differences between words which have substantively the same interpretation.

\section{Main analysis}

As noted earlier, the putative advantage of using ALCESTE for textual analysis is that it provides a standardised method for analysing and comparing texts. The aim here, then, is to apply the same standard analysis to all three corpora. A comparison of results is intended firstly to provide an indication of the suitability of ALCESTE as a research tool in respect of these different forms of textual data. Secondly, the aim is to discover the similarities and differences in the representations of biotechnology that circulate in the spheres of communication embodied in the three corpora. ALCESTE partitions a corpus of text into a number of 'lexical classes'. It does this using an 
algorithm known as 'classification descendante hiérarchique' (CDH). The process is similar to a hierarchical cluster analysis except that the process is reversed. In CDH the corpus is first partitioned into two classes of words that significantly co-occur. This process is repeated for each of the resulting branches until a terminal classification is arrived at. The criterion for deciding if and where to partition each branch is based on the ${ }_{-}^{2}$ value of a crosstabulation of words and ECUs. The result - the terminal classifications of significantly associated words - constitutes the principal material for interpretation, as well as a correspondence analysis of characteristic words and passive variables for each corpus. Despite the quantitative approach taken in the derivation of this material, the interpretation should nevertheless be considered as a qualitative one as we are not able to make specific inferences from our sample to a population.

The analyses were all carried out using ALCESTE's default parameters, with the exception of the open question responses. Because of the brevity of each of these responses, ALCESTE was programmed to take each whole ICU (i.e. response item) as an ECU. This was done because it was found that many of the very short (one or two word) responses were omitted from the analysis altogether when the length of each ECU was calculated automatically by the program. In all other respects the analyses run on ALCESTE were exactly the same for each corpus, differing only in the manner of their preparation as described previously.

\section{Supplementary analysis - open questions}

The open question corpus included identification numbers for each response. After running the ALCESTE analysis, one of the resulting output files was imported into an Excel spreadsheet. This file linked each ID number to the lexical class of which each analysed response was a member. After stripping out all other unwanted cells from the file it was imported into a new SPSS data file. Finally, this new file was merged with the original Eurobarometer data file to create a new variable which represented the ALCESTE classification for each case. The open question responses had previously been analysed using classical content analysis. One of the variables from this analysis measured respondents' evaluative judgment of biotechnology in four categories from negative to positive. In order to assess the construct validity of the ALCESTE 
classifications a correspondence analysis was carried out using the latter variable, along with the ALCESTE classification variable, in the column and row respectively. If our hypothesis is that the ALCESTE method of analysis produces results which are semantically coherent, we would expect that the classical content analysis coding and the ALCESTE classes to associate comparably on the same dimensions. 


\section{Results}

A summary of the basic statistics relating to each corpus is given in table 2 . It can be seen that the 'raw' word counts for each corpus are different, ranging from the focus groups down to the open questions. The latter represent the smallest word count due to the nature of the short responses in the data. All three corpora satisfy the minimum recommended word count. A different pattern emerges when looking at the number of unique words in each corpus. Here the ordering reflects the range of vocabulary employed in each setting. In the most informal setting, the open questions, the vocabulary is the most limited. Only 452 unique words were eligible for analysis. This also reflects the short nature of the responses, and their very specific focus. The news media data exhibited the widest range of vocabulary. This is an unsurprising result as one would expect written communication to employ a greater variety of language than verbal forms.

table 3

Alceste analyses: basic information

\begin{tabular}{|c|c|c|c|}
\hline & News media & Focus groups & Open questions \\
\hline $\begin{array}{l}\text { Total word } \\
\text { count }\end{array}$ & 34550 & 44958 & 12365 \\
\hline $\begin{array}{l}\text { Unique words } \\
\text { analysed }\end{array}$ & 1312 & 946 & 452 \\
\hline $\begin{array}{l}\text { Passive } \\
\text { variables }\end{array}$ & 10 & 13 & \\
\hline I.C.U.S & 76 & 5 & 973 \\
\hline $\begin{array}{l}\text { Classified } \\
\text { E.C.U.s }\end{array}$ & 823 & 934 & 741 \\
\hline $\begin{array}{l}\text { Stability } \\
\text { coefficient }\end{array}$ & .87 & .83 & 1 \\
\hline $\begin{array}{l}\text { Lexical } \\
\text { classes }\end{array}$ & 4 & 4 & 6 \\
\hline $\begin{array}{l}\text { Distribution } \\
\text { of classes }\left(\frac{\circ}{0}\right)\end{array}$ & $\begin{array}{lr}\text { A } & 16.39 \\
\text { B } & 17.79 \\
\text { C } & 7.98 \\
\text { D } & 57.84\end{array}$ & $\begin{array}{ll}\text { A } & 16.07 \\
\mathrm{~B} & 19.79 \\
\mathrm{C} & 19.67 \\
\mathrm{D} & 44.47\end{array}$ & $\begin{array}{lr}\text { A } & 18.08 \\
\text { B } & 17.27 \\
\text { C } & 16.06 \\
\text { D } & 6.75 \\
\mathrm{E} & 21.32 \\
\mathrm{~F} & 20.51\end{array}$ \\
\hline
\end{tabular}


The passive variable counts show the number of tagged indicators in each corpus. The ten variables in the news media set represent the ten publications sampled. For the focus groups each variable represents a demographic attribute. For this corpus, multiple ICUs can include one or more of the same variables e.g. more than one of the five focus groups was tagged as including 'environmentally-aware' participants. This is not so for the news media, where each of the 76 ICUs is attributable to only one publication.

The count of classified ECUs is given, along with a stability coefficient. ALCESTE makes two preliminary analyses using context units of slightly different lengths. The length finally adopted is a function of the proportion of ECUs that can be successfully classified compared to the total available. The stability coefficient measures the proportion of ECUs that are allocated to the same class in each of these analyses. A low coefficient would indicate a corpus which does not include words which are strongly and consistently associated with each other. Here all three corpora exhibit a high degree of stability and we can therefore assume that the classes identified are reliable representations of the texts, at least on the internal criteria defined by the program.

As can be seen from table 3, four classes have been identified for both news media and focus group texts, while six have been identified from the open question responses. The news media corpus has the most asymmetric distribution, with $57 \%$ of ECUs falling within one class. The open question data show a more even distribution than the other two sets.

\section{Lexical classes}

\section{News media}

Table 4 shows the most characteristic words from each defined lexical class. The largest class (D) consists mainly of relatively neutral discussion of the activities of scientists across a range of biotechnology applications. DNA is the most characteristic word of this class. Inspection of the most characteristic ECUs from each class (see 
appendix) shows that DNA figures highly in technical discussions about biotechnology. It also forms part of a widespread media focus on DNA 'fingerprinting' techniques in criminal investigations in Britain. None of the twenty most characteristic ECUs had a strongly ethical focus, but most portrayed science and scientists in a neutral or mildly positive light. The association of this objective/scientific class with the tabloid press (figure 2) perhaps indicates a trust in science as a benign force in popular imagination.

Another class (A) centred on applications relating to general medicine and, specifically, to reproduction. The representation of reproductive issues such as screening embryos and in vitro fertilisation shows a strong ethical dimension, such as in the following example:

In a pluralistic society it is reasonable to allow individuals to take decisions which affect only them and their families. Spurious arguments about practising eugenics, about slippery slopes, about designer babies, are a poor reason to prevent work doing much to promote healthy life.

The words 'moral', 'dilemma', 'future' are all associated on this class which tends to reinforce the idea that biotechnology here is seen as something of a 'Pandora's box' that needs consideration from an ethical point of view. Figure 2 shows that the Independent and Guardian newspapers are associated with this class.

Class (B) is defined on an association with food issues and particularly genetically modified soya and debates around food labelling. This partially reflects the contemporaneous salience of a particular news story relating to genetically modified U.S. soya beans. The common representation here is one of genetically modified food from a 'consumer' standpoint. The strongly moral representation of the medical and reproductive applications is missing here.

Class (C) is highly specific and relates to a high-profile speech made by Prince Charles about organic farming. Being so specific it is of less relevance than other lexical classes for the purposes of the present study. As can be seen from table 3 it is also by far the smallest of all the classes. The fact that this theme emerges so clearly in the 
sample illustrates the fact that corpora of news items reflect very strongly the thematic foci of the sample. Certain themes (such as Prince Charles's speech) may be highly salient as news for a limited period of time without necessarily implying a more permanent dimension of concern. In a longer research project one could get around this by employing a longitudinal sampling design.

Looking at the 'map' of words in figure 1 we can see that factor 2 accounts for about $30 \%$ of the inertia of the correspondence table (inertia is defined here as a measure of dispersion of the row and column profiles in multidimensional space (Greenacre \& Blasius, 1994)). One might interpret this as a dimension indicating intensity of moral/ethical concern. It ranges from low: words in class D, to high: words in class A. 
table 4

News media: characteristic words ordered by strength of association

\begin{tabular}{|c|c|c|c|}
\hline $\begin{array}{l}\text { Medical/Reproduction } \\
\text { (A) }\end{array}$ & Food (B) & $\begin{array}{l}\text { Modern farming } \\
\text { [Prince Charles] (C) }\end{array}$ & Objective/scientific (D) \\
\hline embryo+(23) & bean+(25) & agriculture+(13) & $\operatorname{dna}(49)$ \\
\hline insur+(10) & crop $+(20)$ & bse(11) & $\mathrm{up}(40)$ \\
\hline screen+(11) & food $+(43)$ & charles $(10)$ & blood+(22) \\
\hline twin $+(10)$ & genetic+(71) & farm+(37) & body+(29) \\
\hline woman+(16) & labell+(16) & modern(10) & cell+(37) \\
\hline abortion+(8) & maize(13) & prince $+(22)$ & drug+(29) \\
\hline breast+(8) & manipulat+(15) & $\operatorname{soil}(7)$ & $\operatorname{mice}(22)$ \\
\hline test+(25) & modified(37) & $\operatorname{speech}(12)$ & pig+(26) \\
\hline age $+(9)$ & plant+(26) & welfare(6) & research $+(58)$ \\
\hline allow $+(7)$ & product $+(29)$ & environmental+(7) & start+(15) \\
\hline babies(10) & $\operatorname{soya}(31)$ & organ $+(16)$ & vaccine $+(17)$ \\
\hline couple+(9) & sell.(10) & polic+(5) & work+(38) \\
\hline cystic(9) & contain+(16) & price $+(6)$ & into(61) \\
\hline disease $+(25)$ & herbicide+(10) & reform(4) & break.(9) \\
\hline disorder+(6) & oilt+(11) & crisis(3) & breed.(20) \\
\hline fibrosis(9) & resist+(18) & ministry(4) & take.(36) \\
\hline foetus(7) & supermarket+(14) & september(4) & appear+(9) \\
\hline womb(6) & allerg+(10) & wales(3) & attack+(16) \\
\hline affect+(7) & foodstuff $+(7)$ & pay.(5) & cattle(14) \\
\hline $\operatorname{born}(7)$ & harvest+(9) & address+(3) & creat+(23) \\
\hline boy+(4) & label+(7) & associat+(6) & $\operatorname{each}(18)$ \\
\hline diagnosis(5) & roundup(7) & cornwall(2) & fat(15) \\
\hline dilemma+(5) & sainsbury+(7) & divorce(3) & game+(9) \\
\hline doctor+(11) & seed $+(7)$ & europe+(9) & heart+(18) \\
\hline dystrophy(4) & american+(11) & exploit+(3) & $\operatorname{hiv}(14)$ \\
\hline famil+(8) & borer(5) & offence+(2) & immune(14) \\
\hline hereditary(4) & bread $+(5)$ & point+(6) & inject+(11) \\
\hline informat+(6) & ciba+(6) & principle $+(2)$ & institute $+(11)$ \\
\hline inherit+(7) & committee $+(6)$ & view+(5) & kidney+(13) \\
\hline $\operatorname{ivf}(5)$ & consumer+(9) & hit.(3) & $\operatorname{man}(13)$ \\
\hline life(18) & engineer+(23) & animal+(10) & milk+(19) \\
\hline moral+(8) & $\operatorname{fagan}(6)$ & bill+(3) & molecule+(9) \\
\hline muscular(4) & flour+(6) & cheap+(4) & obesity(14) \\
\hline pregnanc $+(5)$ & fruit+(8) & consider+(3) & sheep+(13) \\
\hline pregnant(4) & garden $+(5)$ & $\operatorname{god}(3)$ & system+(22) \\
\hline preimplantation(4) & introduce+(10) & intensive $+(3)$ & university(16) \\
\hline premiums(4) & monsanto $+(5)$ & land+(3) & white+(9) \\
\hline society+(10) & nut+(5) & law+(2) & build.(8) \\
\hline termination $(5)$ & process+(13) & method $+(5)$ & fight.(7) \\
\hline turner_s(5) & shelves(5) & night(2) & lead.(25) \\
\hline $\operatorname{vary}+(4)$ & tomato $(5)$ & pesticide $+(5)$ & put.(15) \\
\hline wide $+(6)$ & buy.(5) & pollut $+(3)$ & aid+(12) \\
\hline winston+(4) & make.(24) & public+(5) & $\operatorname{approach}(7)$ \\
\hline seek.(4) & advisory(4) & significant+(2) & base+(7) \\
\hline see.(12) & alter+(7) & sustain+(2) & brown+(7) \\
\hline birth+(4) & apple+(6) & union+(3) & chillingham(7) \\
\hline cancer+(13) & arrive+(4) & vegetable+(4) & discover $+(14)$ \\
\hline case+(9) & brazil(4) & viol+(3) & explain+(8) \\
\hline certaint $+(5)$ & choice+(5) & cost.(3) & $\operatorname{fosb}(7)$ \\
\hline children+(8) & clear+(8) & stand.(2) & infect+(15) \\
\hline defect $+(6)$ & commercial+(5) & $\operatorname{adopt}+(2)$ & laborator+(13) \\
\hline embryology(3) & $\operatorname{corn}+(5)$ & campaign+(2) & ladder+(8) \\
\hline
\end{tabular}




\begin{tabular}{llll} 
employ+(5) & enzyme+(5) & cent+(7) & live+(15) \\
faith(3) & frankenstein(3) & continue+(2) & malar+(7) \\
\hline
\end{tabular}

\section{figure 1}

News media: correspondence analysis of characteristic words

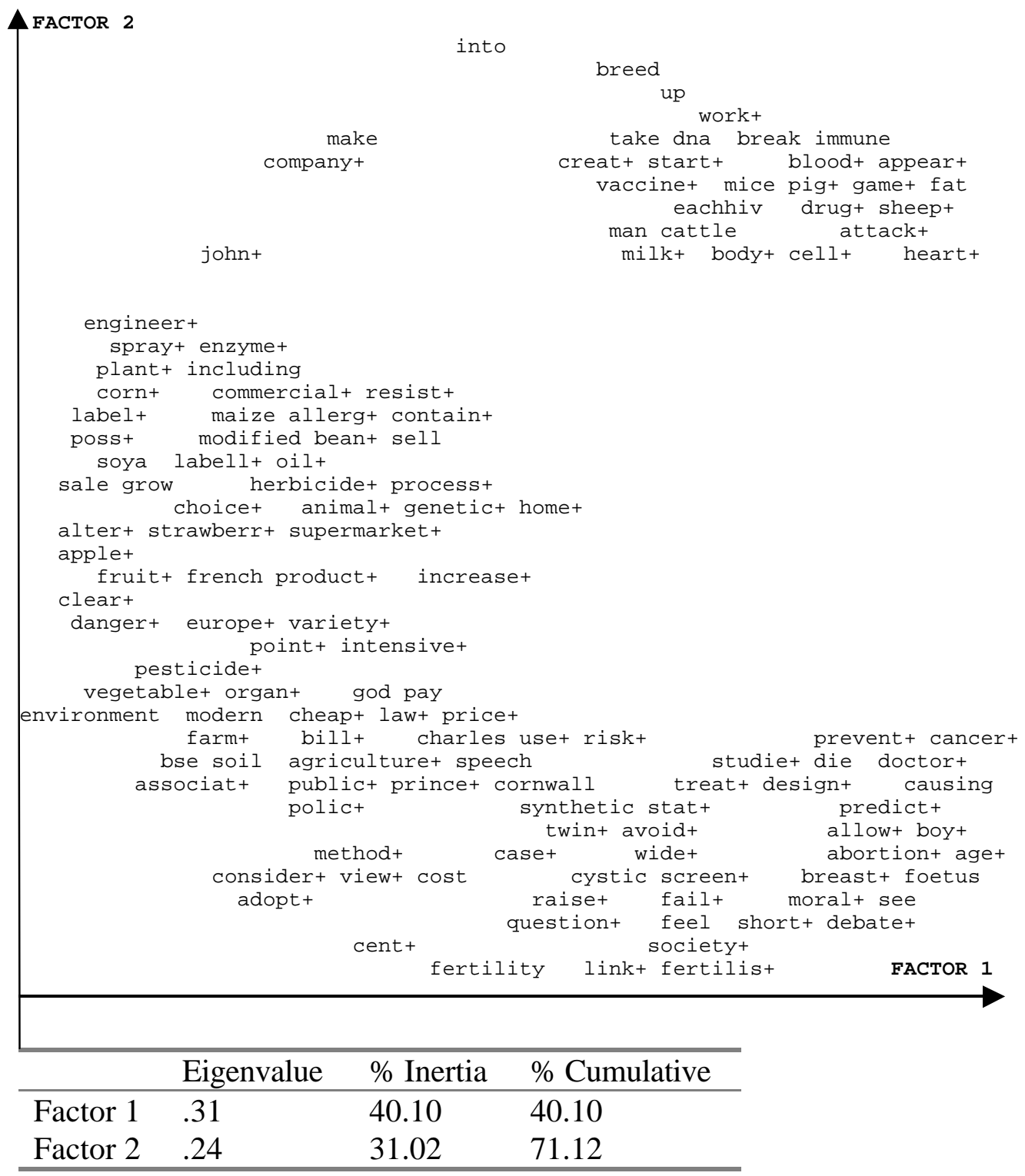


figure 2

News media: correspondence analysis of lexical classes and publications

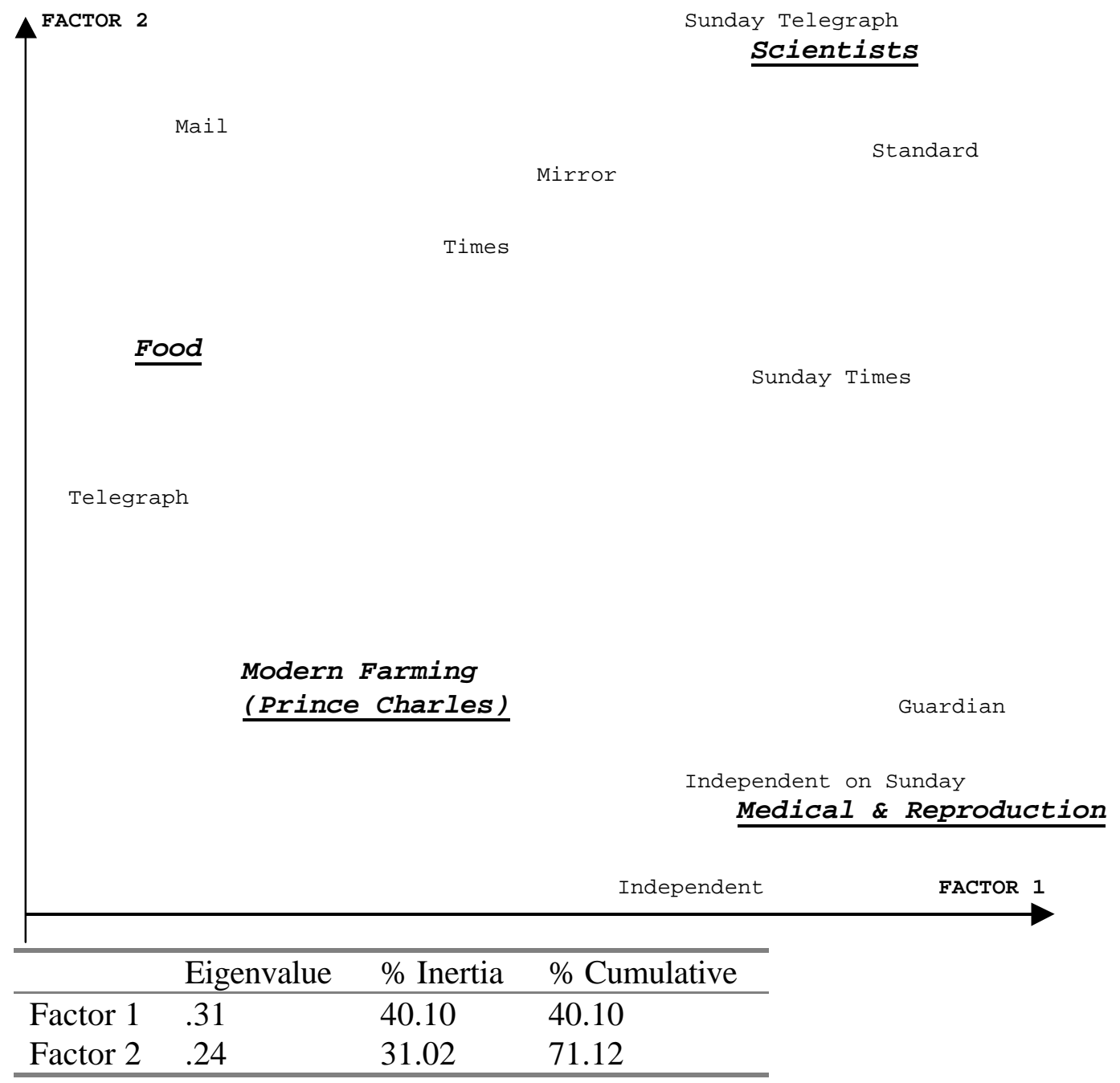




\section{Focus groups}

The four classes defined by ALCESTE are shown in table 5. Each class is relatively homogeneous in its distribution of vocabulary. It was thus felt possible to unambiguously name classes A to D as transplantation, reproduction, food, regulation. That the classes should be so clearly marked in this corpus is not particularly surprising when one considers the nature of the data. Although the moderator's dialogue has been removed from the transcriptions, each group's discussion is being led through a topic guide which follows essentially the same pattern on each occasion. It is nevertheless useful to note that ALCESTE has successfully picked out this pattern when simultaneously analysing all the groups' transcriptions together.

Class A clearly refers to conversation around the use of organs transplanted from animals to humans. The most highly associated words are 'breed', 'animal', 'heart', 'human', 'pig+', 'transplant+'. Interestingly it seems that, in contrast to the neutral way in which the newspapers framed the issue, there is a significant concern with the ethical considerations in breeding animals for the purpose of providing organs for transplantation, e.g.

do we accept that we're going to breed a spare parts bin, do we accept that it is right to take those parts and put them into anything we so desire, be it a human being, another animal, whatever?

Looking at figure 4, class B, which has a focus on reproduction, is strongly associated with the female variable in the correspondence plot. One cannot infer too much from this, however, as there was only one all female group. An attempt to tag each participant individually in all groups by gender was made during analysis, but unfortunately failed when the program repeatedly crashed because of the tagging used. There is no doubt that this particular group did focus on reproductive issues very strongly. It is also interesting to note that the discourse, apparent from the typical examples provided in the analysis, surrounds the choices, practical and ethical, which present themselves to women when faced with the possibility of genetic screening, in 
vitro fertilisation and other related applications of biotechnology. This mirrors the way in which these technologies are presented in the press according to our analysis of the news media corpus.

Food is associated with class C. The forms 'genetic+', 'modified' and 'tomato' are all highly characteristic. This is undoubtedly due to the specific topic of discussion being a new range of genetically modified tomato products as examples of an application of biotechnology. Forms like 'cost', 'benefit' 'buy', 'supermarket', 'label', corroborate the representation of genetically modified food, already observed in the press analysis, as a consumer issue as opposed to the strongly ethical frame in which we see transplantation and reproduction.

Regulation appears as a distinct class in this corpus. As in the case of food, the moderators asked each group about their views as to who should regulate biotechnological applications. Characteristic ECUs show government and scientists seen as representing two poles of authority which may be in conflict:

Yes, shady. Shady, and I'm definitely more inclined to pay them [the government] more attention if there's a scientist working for the government; he's not going to have any, he's not going to be working for the government is he?...

Looking at figure 4, we can see that regulation (class D) is situated at the positive extreme of factor 2; at the other extreme are reproduction and transplantation. Food appears between the two extremes, but somewhat closer to latter two classes. Associated on positive and negative extremes of factor 2 are male and female groups. Whilst it is difficult to interpret this factor as a continuum, it clearly shows that the idea of 'regulation' is anchored in a different frame of verbal reference to that of transplantation and reproduction. One might also hypothesise that these three topics have a different salience for females and males. 
table 5

Focus groups: characteristic words ordered by strength of association

\begin{tabular}{|c|c|c|c|}
\hline Transplantation (A) & Reproduction (B) & Food $(C)$ & Regulation (D) \\
\hline breed.(12) & baby(24) & genetic+(49) & government+(34) \\
\hline animal+(31) & boy+(19) & modified(15) & inform+(21) \\
\hline heart+(32) & child $+(32)$ & tomato $(57)$ & research+(24) \\
\hline human+(31) & girl+(12) & food $+(24)$ & come.(61) \\
\hline pig+(19) & $\operatorname{sex}(10)$ & grow.(20) & $\operatorname{bad}(21)$ \\
\hline transplant+(15) & test+(23) & colour+(9) & believe+(14) \\
\hline use $+(30)$ & twin $+(12)$ & energy(12) & bias+(11) \\
\hline clone $+(12)$ & woman+(10) & process+(10) & $\operatorname{church}(9)$ \\
\hline kill+(13) & choose.(11) & vegetable+(11) & decision+(9) \\
\hline purpose+(6) & babies(13) & buy.(16) & idea $+(20)$ \\
\hline sheep $(7)$ & blood+(10) & chemical+(13) & independent(14) \\
\hline vegetarian+(7) & $\operatorname{men}(8)$ & $\operatorname{dna}(8)$ & press+(14) \\
\hline alive(5) & $\operatorname{down}(20)$ & engineer+(19) & scientist $+(24)$ \\
\hline kidney+(5) & $\operatorname{age}(6)$ & farm+(7) & term $+(13)$ \\
\hline medicine $+(4)$ & aware(7) & $\operatorname{fresh}(5)$ & trust $+(17)$ \\
\hline organ+(15) & beef $+(8)$ & imagine(9) & world(18) \\
\hline rear+(5) & boil+(5) & natural+(14) & wrong+(27) \\
\hline reject+(6) & $\operatorname{born}(9)$ & plant+(10) & show.(7) \\
\hline take.(23) & friend $+(7)$ & reduce $+(8)$ & think.(164) \\
\hline cheese+(7) & hair+(7) & spray $+(5)$ & write.(6) \\
\hline create $+(4)$ & husband+(8) & waste(9) & countr+(12) \\
\hline creat+(3) & intelligent(5) & cost.(6) & ethic $+(6)$ \\
\hline difference(7) & mother+(5) & benefit+(7) & everyone+(14) \\
\hline different(16) & pregnant(7) & better+(12) & fund+(10) \\
\hline ear+(6) & sister(5) & $\operatorname{bigg}+(7)$ & job+(6) \\
\hline fair+(6) & $\operatorname{sperm}(7)$ & bother+(5) & $\operatorname{lot}+(18)$ \\
\hline $\operatorname{kosha}(5)$ & young+(8) & changing(6) & $\operatorname{man}(7)$ \\
\hline live $+(8)$ & $\operatorname{out}(32)$ & fruit+(5) & patent+(6) \\
\hline $\operatorname{milk}(4)$ & light.(3) & ingredient+(5) & prov+(6) \\
\hline mouse $+(5)$ & $\operatorname{birth}(3)$ & look $+(17)$ & public+(14) \\
\hline $\mathrm{ok}(5)$ & blond(3) & notice+(4) & regulation $+(6)$ \\
\hline oppos+(4) & blue(3) & nuclear(3) & relat+(8) \\
\hline $\operatorname{order}(5)$ & brother+(5) & produce $+(12)$ & right+(37) \\
\hline part+(8) & burger+(3) & product $+(8)$ & scare+(7) \\
\hline perfect+(8) & chicken+(6) & produc $+(4)$ & side $+(23)$ \\
\hline play+(4) & desperate(4) & $\operatorname{pur}(6)$ & there_s(56) \\
\hline pure+(5) & $\operatorname{egg}+(4)$ & same(22) & whole(13) \\
\hline rabbinical(3) & father+(7) & seed $+(3)$ & year+(30) \\
\hline similar(3) & marry+(3) & $\operatorname{size}(4)$ & up(49) \\
\hline $\operatorname{species}(5)$ & money(15) & taste $+(7)$ & pay.(13) \\
\hline unnecessary(3) & month $+(4)$ & technolog $+(8)$ & angle(4) \\
\hline accept $+(5)$ & $\operatorname{night}(4)$ & tend $+(8)$ & area $+(10)$ \\
\hline artificial+(4) & programme $+(8)$ & wonder+(6) & bma(4) \\
\hline brain+(3) & $\operatorname{room}(5)$ & throw.(3) & bodies(4) \\
\hline cell $+(2)$ & $\operatorname{scan}+(3)$ & understand.(7) & can_t $(35)$ \\
\hline $\operatorname{cow}+(7)$ & school+(6) & effect+(9) & careful+(5) \\
\hline disorder+(5) & she_d(4) & especially(3) & carry+(5) \\
\hline $\operatorname{dog}+(3)$ & soon $+(4)$ & explain+(5) & commission(5) \\
\hline fit(3) & treat $+(8)$ & image $+(4)$ & compan+(4) \\
\hline form $+(5)$ & want+(22) & immediately(3) & develop+(12) \\
\hline hereditary(3) & leave.(6) & kind $+(12)$ & election+(4) \\
\hline life $+(10)$ & mean.(57) & label+(5) & else+(21) \\
\hline little(7) & run.(4) & shape+(2) & influence+(5) \\
\hline
\end{tabular}


figure 3

Focus groups: correspondence analysis of characteristic words

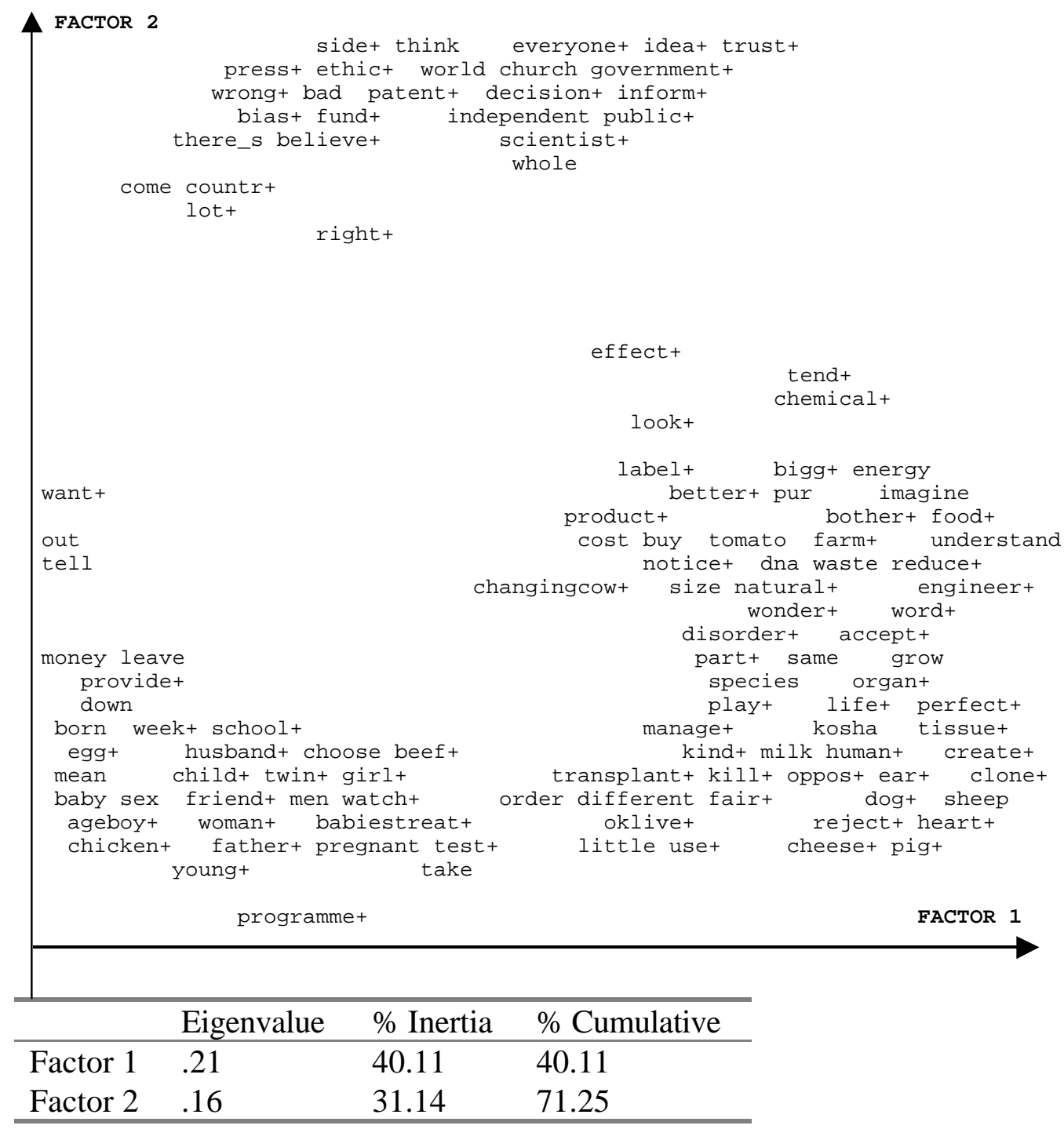


figure 4

Focus groups: correspondence analysis of lexical classes and demographics

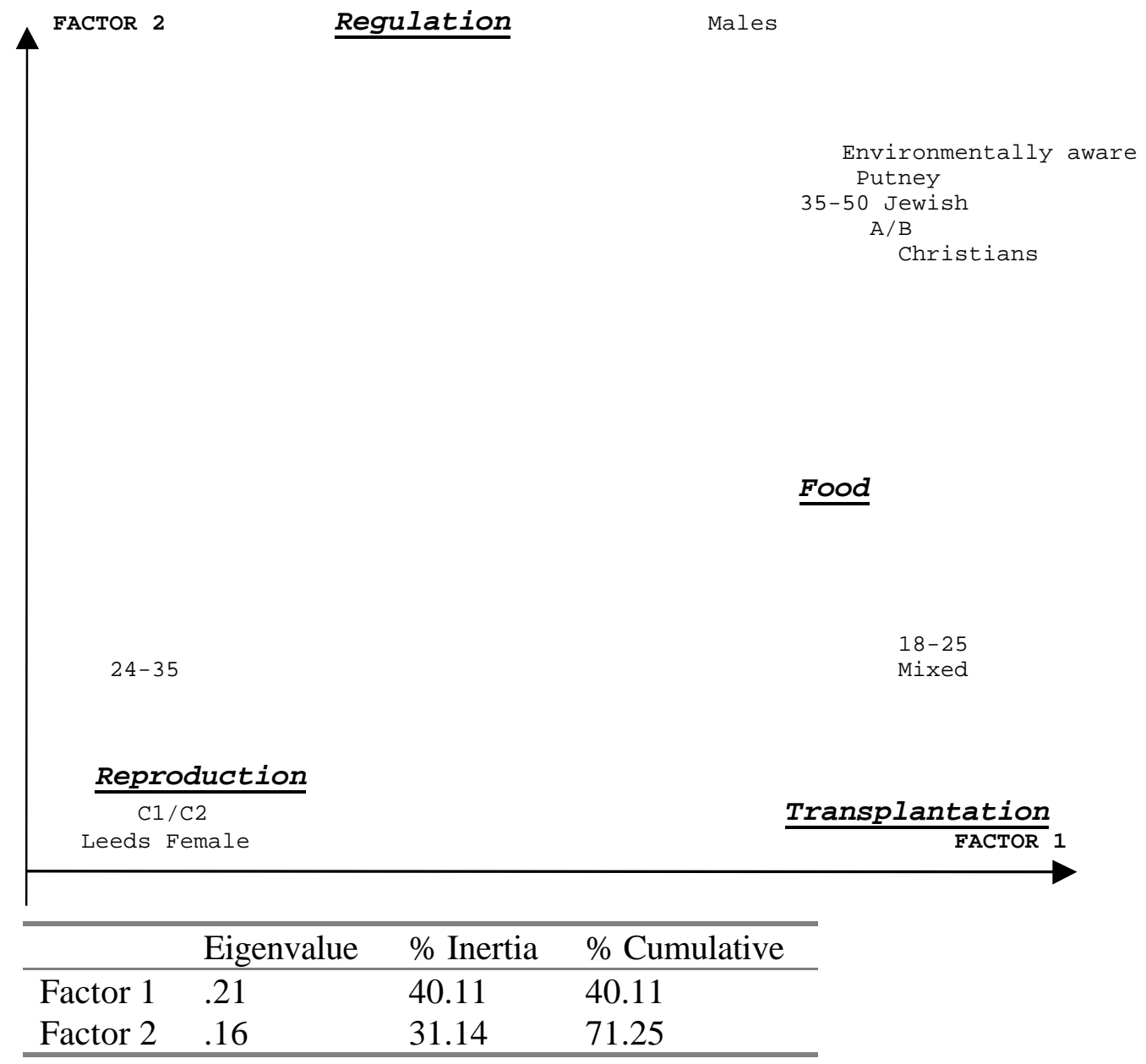




\section{Open question responses}

The question asked was essentially a free association task. This type of data is closer to the theoretical 'ideal-type' envisaged by Reinert and so we should expect reasonable results to emerge. Six classes are defined. The first (table 6, class A) emerges clearly as an association of genetic engineering and 'interfering with nature'. Although this is a background image that is present in the other corpora, it comes out explicitly in this free association setting. The forms 'interfer+', 'mess', 'nature' are all highly associated; the phrase 'playing God' is also found in a number of example ECUs (see appendix). 'Science fiction' is also a common theme, e.g.

science fiction films, bad side of it, dabbling with nature

mutants, I do not agree with it at all; we would not have had BSE if they hadn't bloody well interfered

Class B clearly indicates a proportion of respondents who simply said that they didn't know anything about biotechnology or genetic engineering. The form 'hear+' is most strongly associated on this class which presumably indicates the lack of salience of biotechnology for respondents who often said that they hadn't heard of biotechnology.

The third class (C) indicates a generalised dimension of worry about biotechnology that is not always directed at particular applications, e.g.:

it frightens me, all the horrific changes we could do with it; we could end up making little monsters

very dangerous subject they're getting into; it will create more problems than it will solve

The forms 'genetic' and 'engineering' associate highly on this class. This is possibly due to the way in which the question was phrased. Respondents may simply be 
repeating the words they have just heard. Nevertheless it is instructive to see that the associations made are generally negative.

Class D is clearly centred around reproduction and embryology. Here the 'test-tube baby' metaphor is encountered in example ECUs, and can be inferred from the list of words in table 6 and word 'map' in figure 5.

Curing disease is the main focus of class E. This class represents the most explicitly positive valuation of biotechnology encountered anywhere in all three datasets. This is evidenced in the four most highly associated words, 'cancer', 'cure', 'disease', 'improve'. There is also an element of ignorance in this positive tone, as seen in the association of words like 'solar', 'energy', 'exploration'. Here it appears that people are associating biotechnology with a general faith in scientific progress without really knowing what is meant by the term.

Food appears again, and with a fairly neutral tone, in class E. This is consistent with the way in which food and biotechnology have been linked in the other two corpora. 
table 6

Open question responses: characteristic words ordered by strength of association

\begin{tabular}{|c|c|c|c|c|c|}
\hline $\begin{array}{l}\text { Interfering } \\
\text { w/nature (A) }\end{array}$ & $\begin{array}{l}\text { Don't know } \\
\text { (B) }\end{array}$ & $\begin{array}{l}\text { Unspecific } \\
\text { worry (C) }\end{array}$ & $\begin{array}{l}\text { Reproduction } \\
\text { (D) }\end{array}$ & $\begin{array}{l}\text { Curing disease } \\
\text { (E) }\end{array}$ & Food $(\mathbf{F})$ \\
\hline interfer+(21) & hear.(16) & Engineer+(47) & $\operatorname{artificial(7)}$ & cancer+(20) & grow.(18) \\
\hline mess+(30) & know.(51) & Genetic+(50) & babies(30) & cure+(33) & animal+(36) \\
\hline nature (55) & understand.(16 & put.(8) & inseminat $+(6)$ & disease $+(49)$ & food $+(45)$ \\
\hline around(13) & ) & abuse $+(6)$ & test+(23) & improve+(35) & fruit(12) \\
\hline leave.(11) & else(16) & careful+(6) & tube $+(22)$ & new $+(33)$ & ear+(8) \\
\hline take.(15) & nothing $(40)$ & concern+(8) & pregnanc+(4) & find.(16) & farm+(9) \\
\hline play+(10) & real+(47) & tell.(5) & sperm $+(5)$ & help+(21) & $\operatorname{down}(6)$ \\
\hline trying(12) & can_t(13) & approve(4) & baby+(5) & develop+(13) & bacteria $+(6)$ \\
\hline feel.(5) & idea+(9) & bean+(5) & $\operatorname{dead}(3)$ & drug $+(12)$ & crop+(10) \\
\hline course+(7) & sure (8) & create $+(5)$ & spec+(3) & treatment $+(13)$ & improving $(11)$ \\
\hline $\operatorname{god}(10)$ & mean.(10) & end(4) & woman(4) & energy $(8)$ & plant+(19) \\
\hline go.(17) & say.(5) & soya(5) & worry+(3) & medical+(21) & tomatoes $(8)$ \\
\hline let.(4) & $\operatorname{mind}+(7)$ & they_ve(4) & cloning(5) & medicine+(18) & using(11) \\
\hline alter+(9) & opinion(2) & use+(14) & organ+(4) & prevent $+(7)$ & keep.(5) \\
\hline $\operatorname{bad}(7)$ & risk $+(3)$ & into(11) & pig+(3) & research+(17) & rid.(6) \\
\hline happen+(4) & that_s $(6)$ & to $(48)$ & selection(2) & technolog $+(16)$ & chemical+(9) \\
\hline look+(4) & comment+(1) & get.(8) & human+(7) & aid $+(6)$ & $\operatorname{detect}+(6)$ \\
\hline natural+(10) & word+(3) & give.(6) & manipul+(2) & better(12) & easi+(7) \\
\hline question+(4) & answer(2) & make.(20) & stuff $+(3)$ & childless(4) & environm+(10) \\
\hline $\operatorname{race}(6)$ & hard+(2) & think.(30) & clue(1) & communic $+(5)$ & eradicate(5) \\
\hline eproduction(3) & come.(7) & area+(5) & suppose+(3) & compan+(4) & experim+(12) \\
\hline tamper+(7) & operations (1) & benefit+(7) & biotech+(4) & general+(6) & inherited (5) \\
\hline well(10) & particular+(1); & controll+(6) & creat+(2) & health(12) & insul+(4) \\
\hline agree+(9) & & decisions(3) & transplant $+(3)$ & $\operatorname{solar}(5)$ & life+(15) \\
\hline alone(5) & & frighten+(4) & lose.(1) & work+(7) & $\operatorname{limb}+(3)$ \\
\hline beings(4) & & $\operatorname{man}(4)$ & girl+(1) & cheap+(4) & pest+(5) \\
\hline brain+(3) & & people+(17) & deal.(1) & combat+(3) & quality(4) \\
\hline change $+(7)$ & & problem+(9) & business (1) & computer+(7) & same(5) \\
\hline ethical+(4) & & $\operatorname{right}(6)$ & design+(1) & couples $(4)$ & shelf(4) \\
\hline fiction(3) & & want+(7) & embryo+(1) & eliminate $+(4)$ & side+(5) \\
\hline gene+(13) & & bring.(3) & foodstuffs(1) & elimin+(4) & $\operatorname{veg}(5)$ \\
\hline science+(7) & & birth+(4) & illness(1) & exploration(3) & vegetable+(9) \\
\hline super(3) & & cause+(4) & moment(1) & fertility(6) & eat.(5) \\
\hline thing $+(37)$ & & different (5) & relation+(1); & future (7) & advance+(7) \\
\hline women(4) & & difficult+(3) & & illnesses(6) & biolog+(3) \\
\hline $\operatorname{wrong}(7)$ & & genetically(5) & & $\operatorname{main}+(4)$ & $\operatorname{body}(6)$ \\
\hline $\operatorname{born}(3)$ & & happy(3) & & $\operatorname{modern}(4)$ & cow+(3) \\
\hline way+(11) & & issue+(4) & & profit+(4) & example+(3) \\
\hline child $+(3)$ & & $\operatorname{lot}+(8)$ & & progress+(5) & growth(3) \\
\hline film+(2) & & moral+(5) & & hereditary (5) & long+(10) \\
\hline keen(2) & & poss+(5) & & live+(4) & replacement(2) \\
\hline worrie+(4) & & produce $+(7)$ & & ahead(3) & resist+(5) \\
\hline abort+(2) & & scientist $+(5)$ & & knowledge(3) & result+(3) \\
\hline $\operatorname{eggs}(2)$ & & worse(3) & & $\operatorname{living}(4)$ & sort+(7) \\
\hline mucking(2) & & breed.(5) & & maybe(3) & technique+(3) \\
\hline population(2) & & dangerous+(4) & & world (5) & defects(4) \\
\hline $\operatorname{try}(2)$ & & form (3) & & over(3) & effect+(6) \\
\hline type+(3) & & great+(4) & & ability(2) & product $+(7)$ \\
\hline years(3) & & hand $+(3)$ & & basically(3) & proper+(4) \\
\hline condition+(2) & & necess+(3) & & curing $(2)$ & chain(3) \\
\hline disabilit+(2) & & subject+(3) & & fertilis+(4) & changing(7) \\
\hline field(2) & & substance+(2) & & jobs(2) & industry(3) \\
\hline
\end{tabular}


figure 5

Open question responses: correspondence analysis of characteristic words

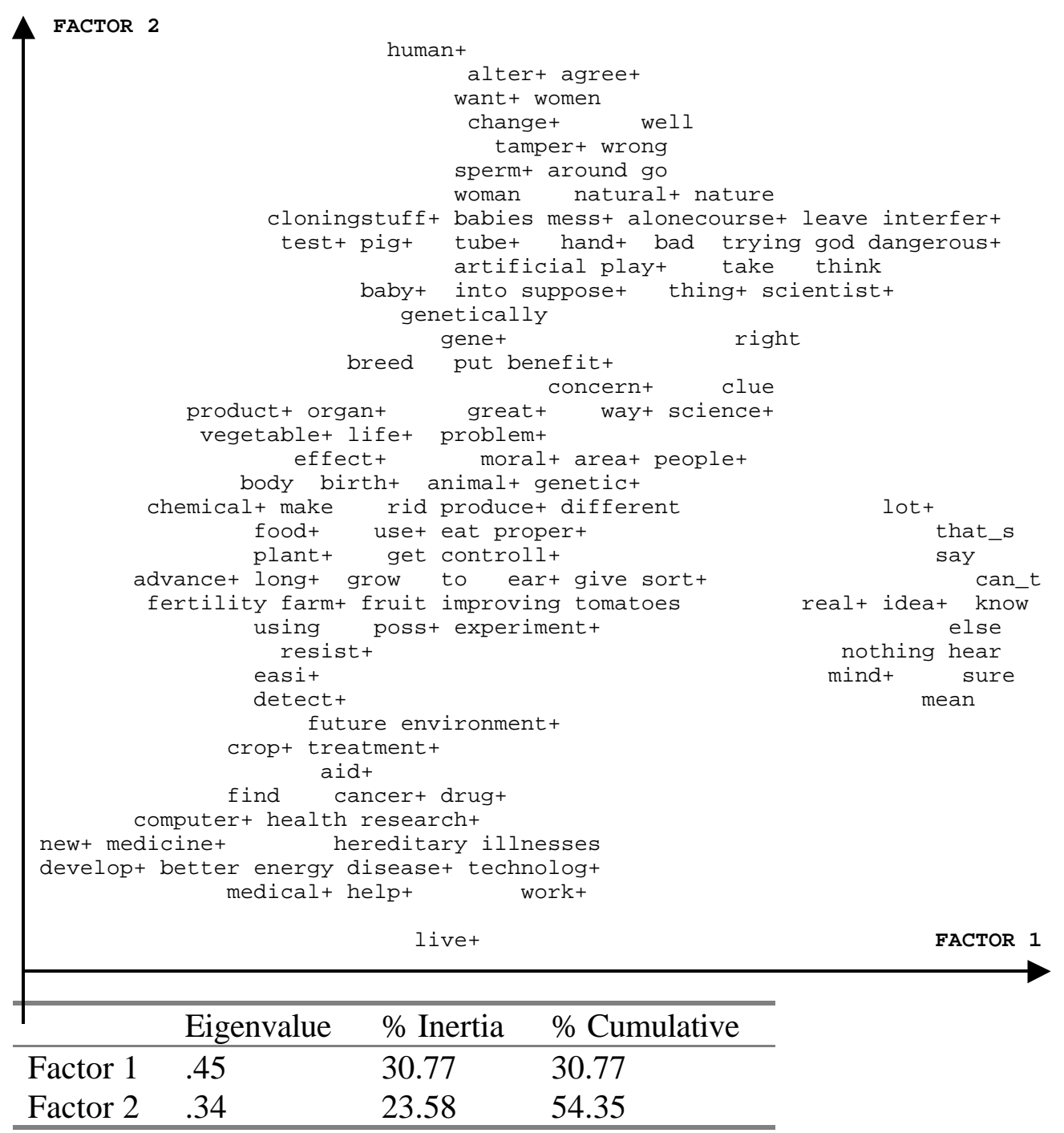


figure 6

Open question responses: correspondence analysis of lexical classes

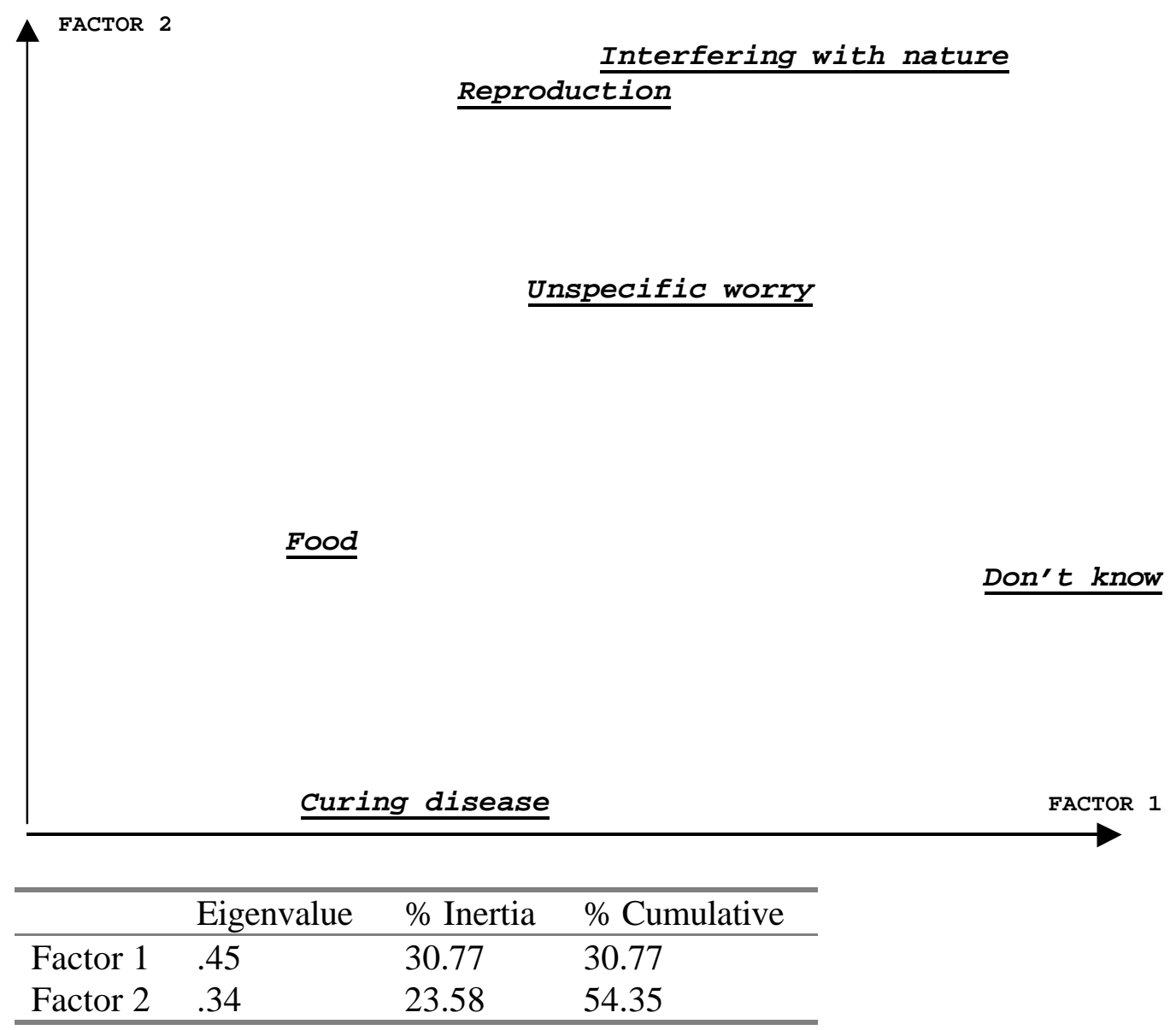




\section{Comparison of classical content analysis and ALCESTE classification}

Figure 7 shows the joint plot from the correspondence analysis derived from crosstabulating ALCESTE's lexical classes with a variable from the Eurobarometer that comes from a classical content analysis of the open question responses. The categorical variable measures respondents' valuation of biotechnology and has four levels - positive, neutral, ambivalent, negative. As can be seen from figure 7, the lexical classes and line up along factor 1 (which accounts for $72.7 \%$ of the inertia) in a way that is highly consistent with that of the manually coded variable. This factor has interfering with nature and negative at one extreme and curing disease and positive at the other and could be interpreted as a continuum of evaluative judgment of biotechnology. Respondents whose answers were not classed by ALCESTE are included in the analysis and occupy a middle point on this continuum. On this evidence one might reasonably conclude that the rationale for using word co-occurrences is justifiable and that ALCESTE manages to accomplish the task of defining groups of words which correspond to semantically coherent categories. 
Figure 7

Open question responses: correspondence analysis of lexical classes and classical content analysis coding (valuation of biotechnology)

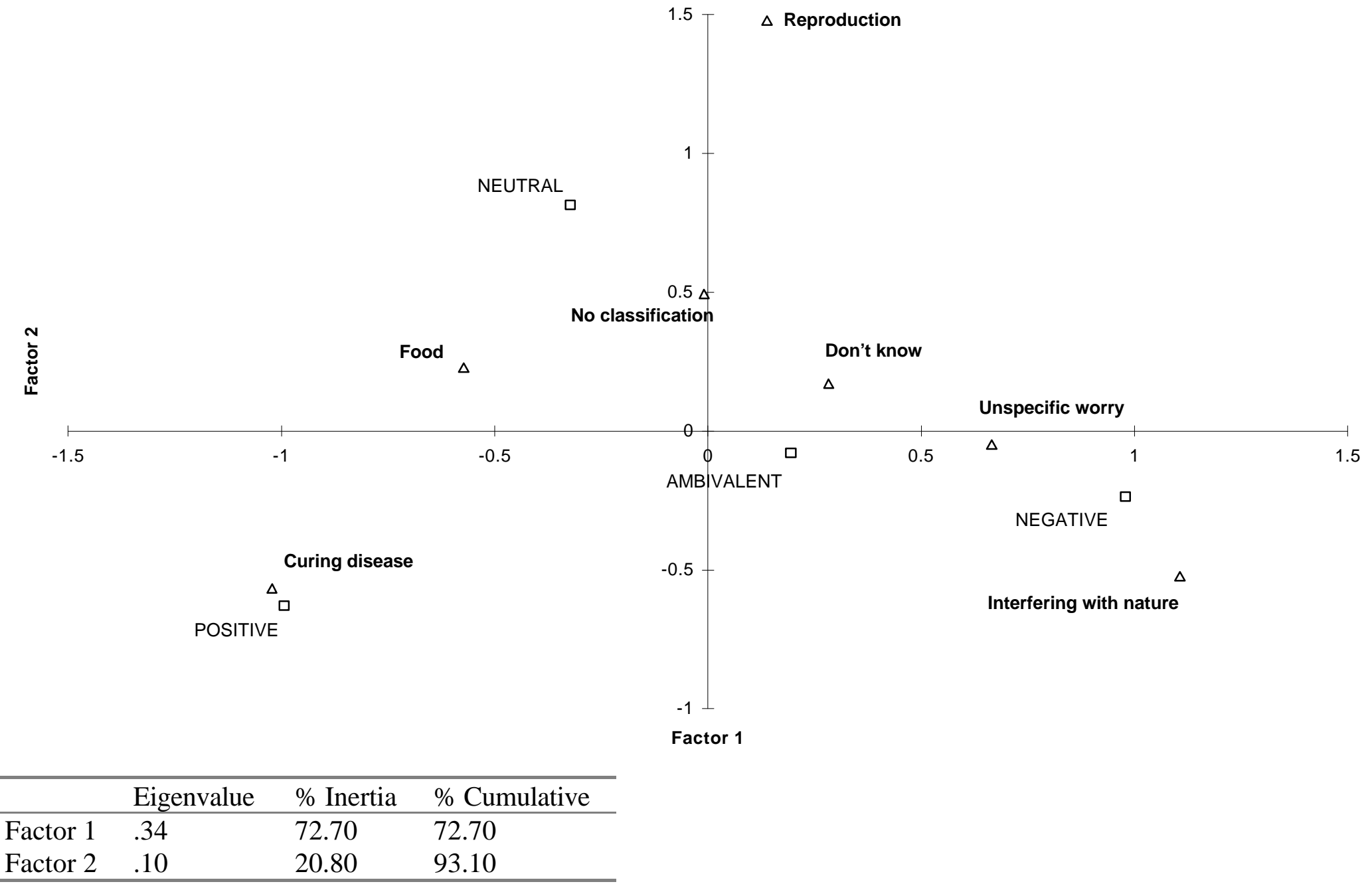




\section{Discussion}

\section{Biotechnology and social representations}

Moscovici distinguishes social representations from Durkheim's 'collective representations' because of their dynamic nature. Twentieth century forms of communication and social interaction imply a much greater fluidity and rate of change of widely distributed beliefs than was the case in the late Nineteenth century when Durkheim wrote on collective representation. If social representations theory can be a useful heuristic device for the study of social phenomena one of its strengths must be this focus on dynamic processes. In the present case we have undertaken a small exploratory study of popular views about modern biotechnology in the form of an historical snapshot of Britain in 1996. Clearly there is no empirical evidence available to illuminate directly the dimensions of change over time in such representations as there are of biotechnology. But if the theory proposes, as it does, that, over time, people will anchor unfamiliar concepts in those that are more familiar, based on their concrete life-experience, we can hazard a reasonable guess at the maturity of such representations according to the extent to which they are already anchored in concrete things.

The comparison of results from each of our three corpora brings to light a relatively consistent set of themes across the different forms of communications represented by the texts. In the sphere of formal communications, in the newspapers, there is discussion, distributed across tabloids and broadsheets, which is informative and non-judgmental on the merits and demerits of biotechnology. This accounts for over 50\% of the analysed corpus. But specific themes are discernible also. Reproduction is linked with general medical applications; food, crops and farming also appear as strongly defined areas. Associated with reproductive and medical issues are a set of largely unresolved ethical questions such as 'do we have a right to choose what type of child we want?' The focus group data show that reproductive applications of biotechnology are again clearly defined and obviously have some salience for the participants involved. Food appears again as a clearly discernible theme. As already noted in the last section, the moderator has a strong effect on the direction of conversation in a focus group setting; but what is interesting here is that the participants talk about genetically modified food with a consumer orientation that is similar to the mode of presentation in the newspapers. The theme of animal-human 
transplantations emerges in a moral context much stronger than in the newspapers. The Eurobarometer data form a representative sample that strongly corroborates the results gained from the qualitative data of the other two corpora. Themes of food, reproduction and moral concern about transplantations and biotechnology in general all emerge. It is in this free association context that some pervasive metaphors emerge. Test-tube babies, playing God, interfering with nature are common responses. In each corpus 'genetic engineering' appears as one of the ten most common repeated phrases.

If we take the frequency, ubiquity and sequence of occurrence of words, phrases and themes to constitute the criteria for identifying the nucleus of a representation (Pereira de $\mathrm{Sa}, 1996)$ then our results indicate that three concrete components to such a nucleus exist with respect to biotechnology - animal-human transplantation, reproductive genetic technology and food applications. Furthermore, this nucleus is signified by the phrase 'genetic engineering' as opposed to 'biotechnology'. Of course, further research using other methods such as repeated interviewing would be desirable if not necessary to corroborate this hypothesis satisfactorily. And, as mentioned earlier, these results provide only a 'snapshot' from one particular point in time. But there are notable absences in the findings which support the hypothesis that representations of biotechnology have not yet, in 1996 in Britain, become 'endemic' in Sperber's sense. Biotechnology appears as something whose concepts and scientific implications are in the process of being transformed into, but have not yet become, what could be termed as 'folk knowledge'. Bauer and Gaskell see social representations as operationalisable for the purposes of research via a three-way conceptualisation: subject/object/project. Social representations are integral to the way in which subjects see themselves and an object (in our case, biotechnology) in relation to a project, i.e. an activity, task or problem (Bauer \& Gaskell, 1998). Our results indicate the possibility that social representations of biotechnology are at an early stage of maturity precisely because of the lack of a concrete project relevant to the experiences of most people. And this is evidenced by the relative paucity of metaphors and concrete objectifications observed in the data. Food is anchored in a consumer context: the familiar experience of shopping for the best quality produce, making decisions on what constitutes healthy, good food. But other elements in our provisional nucleus are anchored only vaguely in concrete contexts: transplantations from animals to humans being seen as a type of grisly science fiction; and reproductive issues linking into remote concepts like eugenics, 
'designer', off-the-shelf babies, as well as the more familiar medical connotations. The fact that xenotransplantation is, surprisingly, not yet strongly linked to the concrete context of hospitals, curing diseases and so forth also lends weight to the probability that these representations are highly contingent on the current exposure of the public to biotechnology in practice.

Figure 8

Figurative nucleus

\section{A figurative nucleus for 'Genetic engineering'}

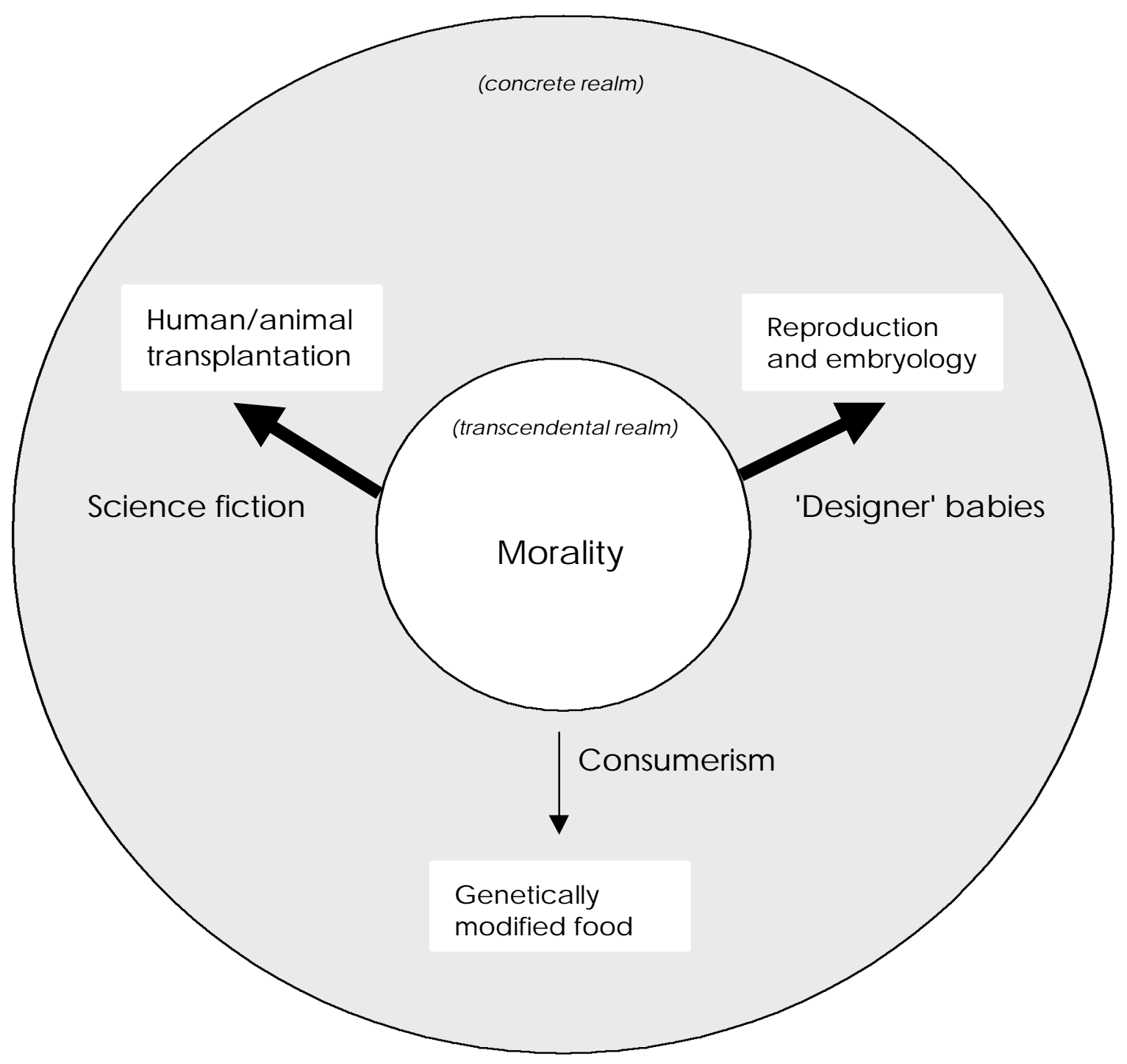


Anchoring is generally referred to within the literature as a type of categorisation process the setting of an unfamiliar idea into a familiar context. These results suggest that this process is at an early stage. But what is also striking is that all the components of the nucleus of representations are 'anchored' in an ethical or moral framework which appears to be widely shared. If it is widely shared it is also familiar; but it is not composed of concrete things so perhaps cannot be thought of as anchoring in Moscovici's sense. However, as it appears to constitute a method through which people communicate and share meaning it would be preferable to retain something of the anchoring concept. One might therefore like to say that representations of biotechnology are 'transcendentally anchored' in a familiar moral framework, but one which is not articulated directly. Figure 8 attempts to summarise what has already been said here in graphical form. The three poles of our proposed figurative nucleus are concretely anchored to varying degrees in the indicated contexts. The degree of anchoring in the familiar moral realm is indicated by the thickness of the arrows.

A logical progression from this exploratory study would be a longitudinal design that might observe the transformation of these representations over a period of time. Exploring the links between collective experience of biotechnology and the way that representations are produced and reproduced might prove fruitful. More interesting still might be research into the nature of the familiar but inchoate moral dimension observed in the present results. Further understanding of this dimension may carry implications for the formation of public policy on biotechnology.

\section{ALCESTE and methodology}

The ALCESTE program works on the assumption which underlies most forms of content analysis: the more frequent the occurrence of a word, the more significant it is for the purposes of interpretation. Additionally it is the degree to which different words frequently occur together that constitutes a second measure of significance. By operationalising both of these principles ALCESTE partitions a corpus of text into lexical classes. The results presented here show classifications that are both interpretable and exhibit a reasonable degree of 'face validity'. The comparison between the classical content analysis and ALCESTE classification suggests that, in this particular analysis at 
any rate, a measure of 'construct validity' was also achieved. Both ALCESTE classes and content analysis coding reflect the same assessment of respondents' valuation of biotechnology on a negative - positive dimension.

Across all three corpora, a relatively coherent pattern of classification emerges. This is due in some measure to the way each one has been sampled. The newspaper articles were sifted manually in order to ensure that their main focus was biotechnology. It is possible that another researcher might use alternative criteria for this selection procedure and this would no doubt affect the nature of the final classifications. This touches on the point that sampling issues in relation to qualitative data are not subject to the same set of agreed conventions that are applied to quantitative material. It is beyond the scope of this paper to address this point in detail. However, it does seem apparent that although a method like ALCESTE is easily replicable for a given sample, one has also to have an agreed method for sampling text in the first place. It is partly for this reason that text obtained through 'free association' is likely to yield the best and most reliable results as far as ALCESTE is concerned. It is easy to see how the choice of articles in the news media corpus and the influence of the moderator in the focus groups will affect the outcome of an ALCESTE analysis. This is suggested by the classifications in the focus group corpus, for instance, where regulation appears as a distinct cluster, although it does not appear in either of the other two analyses. The most likely explanation is simply that the talk was directed to the topic of regulation and that this does not give an accurate guide to the actual salience of the concept for participants. With a free association question these constraints are not present to anything like the same degree. Responses are, of course, influenced to some extent by the way in which the question is asked (this partly explains the frequency of the phrase 'genetic engineering' in the Eurobarometer responses) but the space created for answers is much more of a tabula rasa than for any other method.

Although it has been shown that ALCESTE can produce potentially replicable results with a minimum of prior user-intervention, it certainly does not marginalise the role of the researcher. In a sense, what it does is to shift much of the process of interpretation so that it takes place after the analysis instead of, as in classical content analysis, before - when constructing a coding frame. The scope for differences of interpretation of the results are wide - as they are in most qualitative analysis - but the starting point is, nevertheless, 
transparent and replicable. An obvious application for this method is as a prelude to the construction of a coding frame for a more refined analysis. It has the advantage that a very great quantity of text can be analysed quickly for patterns that may inform the building of more complex theoretical models. ALCESTE's use of correspondence analysis is useful as a quick way of apprehending this information, although our results here did not, in general, seem amenable to the interpretation of meaningful dimensions in the factor spaces defined by the words and classifications. Interpretation of the graphic plots was in this case more akin to that of cluster analysis where it is proximity, not dimensionality, that is being represented.

The ALCESTE program is not a precise tool. It cannot estimate parameters or probabilities. Its analysis is essentially qualitative and can be interpreted quite freely by the researcher. It does, however, provide a transparent and replicable method at least for arriving at a starting point for interpretation which owes much to Benzécri's exhortation that 'the model must fit the data'. Integrating the ALCESTE approach with other more established research paradigms may, on the basis of the present findings, turn out to be a worthwhile endeavour. 


\section{References}

Abric, J. C. (1993). Central system, peripheral system: their function and roles in the dynamic of social representations. Papers in Social Representations, 2, 75-78.

Bauer, M., \& Gaskell, G. (1998). Towards a paradigm for research on social representations : mimeo.

Bechtel, R. (1997). Developments in computer science with application to text analysis. In C. W. Roberts (Ed.), Text analysis for the social sciences: methods for drawing statistical inferences from texts and transcripts . New Jersey: Lawrence Erlbaum.

Benzécri, J.-P. (1973). La place de l'a priori, Encyclopaedia universalis . Paris: Organum.

Bertine, E. (1967). Jung's contribution to our time. New York: C.G. Jung Foundation for Analytical Psychology.

Bourdieu, P. (1979). La distinction. Critique sociale du jugement. Paris: Les editions de minuit.

Doise, W., Clemence, A., \& Lorenzi-Cioldi, F. (1993). The quantitative analysis of social representations. London: Harvester Wheatsheaf.

Evans, W. (1996). Computer-supported content analysis: trends, tools, techniques. Social Science Computer Review, 14(3).

Farr, R. (1987). Social representations: a French tradition of research. Journal for the Theory of Social Behaviour, 17(4).

Farr, R. (1990). Social representations as widespread beliefs. In C. Fraser \& G. Gaskell (Eds.), The social psychological study of widespread beliefs . Oxford: Clarendon Press.

Freud, S. (1917). Introductory lectures on psychoanalysis. Harmondsworth: Penguin.

Galtung, J. (1967). Theory and methods of social research. New York: Columbia.

Garnham, A. (1985). Psycholinguistics: central topics. London: Methuen.

Giegler, H., \& Klein, H. (1994). Correspondence analysis of textual data from personal advertisements. In M. Greenacre \& J. Blasius (Eds.), Correspondence analysis in the social sciences . London: Academic Press.

Greenacre, M., \& Blasius, J. (1994). Correspondence analysis in the social sciences. London: Academic Press.

Jahoda, G. (1988). Critical notes and reflections on 'social representations'. European Journal of Social Psychology, 18, 195-209.

London: Sage.

Krippendorff, C. (1980). Content analysis: an introduction to its methodology.

Markoff, J., Shapiro, G., \& Weitman, S. (1974). Toward the integration of content analysis and general methodology. Sociological Methodology(1).

Moscovici, S. (1984). The phenomenon of social representations. In R. Farr \& S. Moscovici (Eds.), Social representations . Cambridge: Cambridge University Press.

Moscovici, S. (1988). Notes towards a description of social representations. European Journal of Social Psychology, 18.

Pereira de Sa, C. (1996). Determining the central nucleus of social representations. London: Methodology Institute, London School of Economics.

Purkhardt, S. C. (1993). Transforming social representations: a social psychology of common sense and science. London: Routledge.

Reinert, M. (1987). Classification descendante hierarchique et analyse lexicale de contexte - application au corpus de poésies d'Arthur Rimbaud. Bull. Méthod. Sociol. 
Reinert, M. (1998). Alceste users' manual (English version). Toulouse: Image.

Rouquette, M. (1996). Social representations and mass communication research. Journal for the Theory of Social Behaviour, 26(2).

Schiltz, M.-A. (1990). A French reanalysis of a British survey: comparative study of statistical methods applied to social science data (P.055). Paris: CAMS.

Sperber, D. (1985). Anthropology and psychology: towards an epidemiology of representations. Man (New Series), 1, 73-89.

Sperber, D. (1990). The epidemiology of beliefs. In C. Fraser \& G. Gaskell (Eds.), The social psychological study of widespread beliefs . Oxford: Clarendon Press.

Stewart, D. W., \& Shamdasani, P. N. (1990). Focus groups: theory and practice. Newbury Park: Sage.

van Meter, K. M., Schiltz, M.-A., Cibois, P., \& Mounier, L. (1996).

Correspondence analysis: a history and French sociological perspective. In M. Greenacre $\&$ M. Blasius (Eds.), Correspondence analysis in the social sciences . London: Academic Press.

Wagner, W. (1995). How the sperm dominates the ovum - objectification by metaphor in the social representation of conception. European Journal of Social Psychology, 25, 671-688.

Wagner, W. (1997). Word associations in questionnaires: a practical guide to design and analysis. London: Methodology Institute (London School of Economics).

Wittgenstein, L. (1953). Philosophical investigations. Oxford: Blackwell. 


\section{Appendix}

\section{Examples of most typical ECUs in each corpus}

\section{Focus groups}

Clé sélectionnée : A

54840 and off of \#sheep and other things that the abattoirs \#work, whereas one wouldn_t imagine having that many \#pigs to \#transplant \#hearts with, there aren_t the need for them. this is where my \#line is drawn. \#well some \#people would \#feel that it_s oh yes, I \#feel quite happy \#eating \#animals which have been \#killed for my \#use, but I_m not to happy about \#breeding one to \#take it_s \#heart out yes.

67637 but I \#suppose for \#meat they could do that, if they_re doing it for vegetables and \#stuff they could start doing it for \#meat. if you get one with the \#perfect \#meat then you can \#sort of getting \#super \#cows and \#super \#sheep. no, I think that_s \#unnecessary, I don_t \#agree with that.

18334 can I just \#ask, I can_t see the \#difference between \#rearing, if you \#rear an \#animal to \#kill it to \#eat it, is that any \#worse or any better than \#rearing an \#animal to \#use its \#organs, I can_t see one being one being any \#worse than the other.

34534 Y if we \#kill them to \#eat them, I_m sure \#killing them for a longer \#human \#life is a grade above. Y Y I find it a \#strange concept personally. Y yes Y \#vegetarians won_t like it. Y yes, but then I_d rather be \#alive still and have a \#pigs \#heart or \#liver or whatever it is.

54634 whether you_re \#taking the \#heart from a \#human person, you_re \#taking the \#heart when the \#heart is of no \#use to that person because they cannot function even if it_s beating because their \#brain is dead and they_re not viable, whereas with this \#pig,

15631 so I_m very divided on that. I \#suppose you can \#play devils advocate and say it_s a very good \#cut of \#meat and it_s \#heart \#works very \#well in \#humans, now you don_t have to \#kill it yes they did, yes they did, so you_re justifying it just for the \#heart.

54931 you say that but one_s \#life saving and one is sustenance, and you can \#live without the \#meat but you can_t \#live without the \#heart. yes but \#loads of \#people do \#feel that it_s \#perfectly justifiable to \#kill to \#eat and that_s \#sort of the natural \#order of things, don_t they, that was intended, here I \#suppose it \#depends, yes,

63828 I \#take the \#point that I don_t like \#unnecessary \#suffering to \#animals but if it_s for the betterment of a \#human being, I think that_s more important than an \#animals \#life personally so, if it_s for the betterment of \#human health then \#ok,

17026 is a \#transplantation a separate issue from the genetic \#breeding, \#breeding for a \#purpose or \#transplantation, is that a separate issue from the general \#principle of \#cross \#species \#transplantation? is it wrong? I was going to say there are 2 issues there aren_t there, one is do you \#breed something \#purely to \#kill it so you can \#use it as a spare \#parts bin or to \#eat it.

16025 I just think \#well where does it \#stop, do we then \#rear \#sheep who_s \#hearts can be \#transplanted into the \#pigs who_s \#hearts have been \#transplanted into the \#humans, I mean where does it \#stop, and who has the authority to \#take that control, you know.

46625 but the key \#point is for most orthodox jews they_re interested in food that is \#rabbinical certified as \#kosha, therefore if the \#rabbi_s decided, the \#rabbinical authorities decide that this \#cheese is \#ok to \#eat and it has a \#kosha seal on it, then it_s \#ok, 54425 what did I see, something like \#transplanting an \#ear onto a \#rats back or something. something like that. the only thing about growing a \#pig to \#take it_s \#heart away is the fact that you are growing the \#pig to \#take it_s \#heart away, you_re not giving corneal 
graft to anybody, you_re not giving a \#kidney to anybody because you_re \#brain dead,

66525 yes I was going to say I_m sure I_ve read somewhere that someone had a \#pigs \#heart or a \#pig, some \#sort of \#organ that they had. \#artificially grown, I don_t know. the \#ear on the \#mouse. they get the \#human \#tissues or something to grow that on it or something like that, or \#form that \#together but it_s \#actually still the \#pigs \#organ if you see what I mean.

17122 or do you \#breed something, or do we \#accept, if we \#accept that we_re going to \#breed a spare \#parts bin, do we \#accepts that it is right to \#take those \#parts and put them into anything we so desire, be it a \#human being, another \#animal, whatever,

18222 or would you share a \#similar view, would you make a

\#difference between \#organs? no, if by the donation the other person, or the other \#animal continues its being, \#fine, no problems with that at all, but to \#actually \#rear a \#species for them to lose their \#life in \#order to give \#life I think is a \#little bit more dubious.

34122 so you have to do something about that for \#kidney \#transplantation and so on, but with \#animals it_s \#worse, so that in the old days as it were it was never even thought to be a \#possibility to \#use \#animal \#organs, but now you can,

46422 no it_s just quite simply you don_t, the \#dietary laws in their crudest \#form state that you don_t mix meet and \#milk \#together, so if you \#took \#rennet from a \#cows stomach and you shoved it into \#cheese to \#harden it up,

61722 yes it just conjures up, you know, the \#advancement in \#medicine and just the \#amazing things that they can do. \#well they_re using genetic engineering now to prolong the \#life of like vegetable and \#stuff like that, and to grow \#human \#organs on \#different \#animals mainly fro \#transplant later on.

54721 you_re \#taking this \#pig and you_re \#breeding it with the intention of having to \#kill it to produce this \#heart for somebody else. yes, but you_re \#killing an \#animal to \#eat as \#well. the number of \#animals that are \#killed for slaughter is just enormous, you know, the abattoirs are \#working every day and the hide and the other not at the moment they_re not.

Clé sélectionnée : B

80045 because it all \#boils \#down to \#greed at the \#end of the \#day and \#money, if \#you_ve got the \#money you can have what you \#want. I \#mean a far removed example is that guy in the states that \#ran the clinic for, I can_t \#remember what it was called, it \#supposedly was helping \#woman that \#husbands couldn_t for whatever \#reason produce \#sperm to produce a \#baby,

91641 and I_m thinking a 2 \#headed \#baby, you \#know, and it was such a, and I \#mean I was \#tested every \#week, I was having \#twins and $i$ was at the \#hospital every \#week, foetal assessment they called it, and they could \#tell how-much \#blood was in \#each \#baby,

78532 I \#mean if \#you_ve got the \#money you can go and \#choose what \#sex \#baby you \#want, and what colour \#hair and what colour \#eyes it_s got, if \#you_ve got the \#money.

86928 I \#prefer potato at the \#end of the \#day I \#mean I_m not drastic, you \#know, but harry come \#out with a chocolate bar, I \#said where have you got that from, I swopped it, you \#know,

93728 I \#mean it goes to being with \#men in the \#room when you_re having your \#babies, you \#know, I \#mean my \#father wasn_t there when I was \#born, and then my \#father in \#law wasn_t there when my \#husband and his \#sister were \#born,

88624 your own specifications, what you \#want, it_s \#down to you. if \#you_ve got 5 \#boys and you_re \#desperate for a \#girl it_s like, well this is it, yes \#everybody has the right to \#choose what they \#want, you can_t \#say no you can_t have that and you can_t do that,

$94 \overline{2} 24$ you \#know, he \#said I_d like \#boys, but with the first one he was \#desperate for it to be a \#boy, I \#mean my, one of, she_s actually a 
\#friend, it was somebody where I worked who was having a \#baby, and they_d had a \#baby by \#sperm \#donation,

79023 but for other things, I \#mean that_s for sort of health things \#choosing the \#sex of your \#child and stuff like that. but to be \#able to go one \#step and \#choose your \#blue \#eyed, \#blond \#haired, \#intelligent \#child, is going to come \#down to \#money, because you_re going to have to pay somebody because it_s not a necessity.

88722 \#everybody has the right to do what they \#want in a way I \#mean you just visualise, you \#know, the typical \#child \#saying where are we going to get the \#baby from, do you go to \#marks and spencers, eventually you_re going to be \#able to do that,

94522 you \#know. I look forward to \#marks and spencers selling them. over the counter. I_ll have that one there. I \#mean it_s like, I can \#remember somebody, one of my \#friends when she was \#pregnant \#saying I hope it_s not \#ugly because if it_s \#ugly I won_t be \#able to be seen \#out in public with it, and \#everybody, I \#mean yes it was a joke but it was,

65818 exactly, I \#mean if they didn_t try \#out a-lot-of these \#treatments we wouldn_t be where we are now. yes, that_s going, that_s exactly the problem. I don_t agree with that. that_s not \#medical. that_s what I \#mean by, yes no, that_s, that_s definitely I_ll have 4 \#boys with brown \#hair, and 3 \#girls with \#blond \#hair and \#soon you_ll be \#able to \#choose if they_re \#intelligent of sporty or, that_s just, yes.

66118 but I do think if, you \#know, \#woman go for \#fertility \#treatment and they are \#given the option I don_t think that_s a bad thing. well, I_ve seen it on the TV that \#young \#woman are going for this \#treatment, sometimes they_re \#given the option, you \#know, they take \#out the \#eggs and they \#say now we_ve got \#boys and \#girls here which one would you \#prefer,

87018 and he_s got a chocolate bar in his \#hand \#you_ve still got to \#give them \#treat and things, you can_t stop them full stop. I \#mean \#schools have \#stopped having \#beef. $\bar{f}$ yes ours have, yes. and he came \#out and \#said \#he_d had spaghetti bolognaise. \#chicken nuggets that_s all they ever eat, and turkey \#burgers.

89117 yes I think it_s in him, yes, personally. oh no, I_m sure they are \#born that way, no what I \#meant was, I didn_t, I don_t believe that they_re going to be \#able an isolate a gene and \#turn \#round and \#say to \#parents, you \#know, do you \#want this \#child to be \#gay or not.

21216 but \#hospitals refuse to \#tell them what, at the first \#scan or whatever it is, what the \#baby is a \#female or \#male, because of \#fear of it_s a \#female \#they_ll terminate it, and I don_t \#know it in depth but I_ve seen, you \#know,

62916 yes. and can they not \#choose the \#sex of their \#child or whatever. yes they can. they can freeze your, what is it, the genes from your \#mother and you could have the \#egg inserted and \#end up having your \#mother_s \#child or something, you \#know, you just think it_s not natural,

65316 but at the \#end of the \#day if \#you_ve got a \#choice of \#treatment or just living like as you are, it_s \#down to an \#individual what they \#want to do, but it_s nice to have that \#treatment there, you \#know, even if it isn_t like a 100 percent success rate.

77316 P I don_t \#know, something that \#totally mixes me up really, I don_t really \#know what to think about it all, I \#mean when I first fell \#pregnant they \#wanted to do all these \#tests for this that and the other because of my \#age,

80416 but because it was actually the \#head teacher who_d been there 30 odd years who was \#saying that, you \#know rumour had it that they were \#brother and \#sister, had a \#baby and there was actually, it did have, it was actually very, well it was a remedial \#child,

Clé sélectionnée : C

68451 I_m \#sure they can \#make them \#look more juicy and \#bigger. yes, they_re just they_re all the \#same \#size. fake you can have \#fruit 
the \#colour you like or something like that, red \#bananas or he loves it LAUGHTER no, i don_t \#see the point of \#tomato \#pur e though, I mean \#that_s a \#concentrated and preserved, salt banged in it.

22747 so \#immediately the \#benefits of \#using \#genetic \#modified \#tomato are less \#waste and \#reduced \#energy in \#processing, so they_re \#immediately trying to alleviate people_s fears of \#science by back to the nature, it_s quite a \#clever \#marketing ploy.

9040 is that quite \#common in \#sainsbury_s now then? this? and the \#benefits of this is for the manufacturer, so you, so it claims here, less \#waste and \#reduced \#energy and \#processing, so you would \#hope, well the \#benefit should be a lower \#cost.

68532 what are the advantages of \#growing \#tomato? well i mean i can \#imagine, yes that probably means that they get \#better crops. it says here also the \#products are less \#waste and \#reduced \#energy in \#processing, whether it_s an advantage i don_t know enough about it at all, I don_t know, because these are the \#kind of things that, you know,

22930 Y exactly, \#that_s what I_m \#wondering, you know, I_m \#looking at the \#ingredients, it must be something else in there that \#makes this \#same, you know this Y A certain \#seed they can \#reproduce that \#produces the \#same \#tomato, I suppose.

22827 Y I don_t really know how a \#genetic \#modified \#tomato can actually \#reduce \#energy in \#processing or I \#imagine it \#maybe took more \#energy to \#process because of all the \#messing \#around they_ve had to do.

33125 so \#eventually if that is the case then \#farmers will all \#start \#changing \#over to \#genetic \#tomato. Y if everyone_s \#growing the \#same \#tomato then wouldn_t it murder competition which was what I was trying to get at earlier, if everyone was \#growing the \#same \#tomato competition would be Y yes that was what I Y yes, well, could be.

1123 no, and so I can \#see that if you have \#bigger \#tomato I just \#wonder where_s, how are you going to \#make them \#bigger, what else is going to be \#altered in the \#making of it?

45422 a \#plant which has been changed within its own intrinsic \#make up to \#look \#better or \#taste \#better, but you_re actually going to metabolise it exactly the \#same as if you metabolised the \#plant before the \#genetic change well you \#hope you are.

53622 to be talking about \#genetic \#engineered \#tomato in you \#green house except for years and years \#plant breeders and people who raise \#vegetable have been \#selectively breeding \#bigger ones and \#better ones and \#sweeter ones and redder ones, or whatever,

82522 I just \#grow them in my \#green house, so, and I know they_re \#natural. yes I would I think people need to know more about these things, the \#words \#alone frighten a-lot-of people off do you know they have \#genetic \#modified the \#seeds you know, I mean I don_t \#fully \#understand all this \#genetics and \#de \#de \#de,

44520 and therefore I have no problem with that. how-much more out of it do we pay for this \#particular \#benefit? oh really. there_s less \#waste. it_s got fewer \#tomato in it. LAUGHTER. your \#image of the \#genetic \#modified \#tomato is a very \#big one? or a \#fuller one. 2 in 1 \#type of \#tomato.

68020 T I don_t know. yes, I_ve \#seen it, I don_t know, I_d probably stick with the \#tomato at home. the \#benefits of \#using them and $i$ should then \#imagine they_re probably more expensive, aren_t they? yes exactly, the \#cost, value.

69620 it_s the \#kind of, you know, yes like all the \#tomato are going to be the \#same \#shape. yes, \#same \#shape, \#same \#colours, \#same \#size, so you don_t get unfairness or artificial.

69820 I wouldn_t have \#noticed that \#label. no I wouldn_t. no. I would have thought it just said at the bottom \#made of \#tomato and stuff you just assume. just \#over \#looked the \#genetic \#modified. well I don_t know. no no, but it has to stand out, that doesn_t stand out, \#that_s a bit of a cop out.

40318 well I_m \#sure there are, I mean you can do, that we can be \#genetic \#engineering \#over sort of \#tomato and things like that, this 
\#kind of \#business, but \#that_s not what would really come into my \#mind if you just \#threw a phrase at me.

6917 \#genetic \#engineering \#technology or which ever way you \#call it, is \#better than just ploughing on and taking the \#chemical route, and \#that_s why I say I_d be more \#concerned about \#making \#food \#better and more abundant by \#chemical means than I would by \#genetic \#engineering.

67817 and I think you can \#buy them in the \#supermarket can_t you? isn_t it \#tomato puree? do they have to be labelled. \#that_s something I just wouldn_t \#buy, you \#see. \#genetic \#modified. no I haven_t \#seen these before. no. i just wouldn_t you wouldn_t \#buy it because it says \#genetic \#modified.

67917 you wouldn_t. I would not \#buy that, no, that would be something I would steer clear away from. I would have thought they_d be \#better quality \#tomato. \#genetic, just the whole term, \#genetic \#engineered. T if it was the \#same \#price I_d probably say that I would \#buy it, because I would have thought they_d be \#better quality.

Clé sélectionnée : D

13817 certainly as far as I_m concerned. there are \#lots of \#pressure \#groups, I mean the \#bma is perhaps one of the, conspiracy, it_s one of the most influential \#pressure \#groups, \#interest \#group, currently in this \#country, but it_s very influential, and \#rightly so, in \#terms of \#ethics,

60113 no. no. I \#think it_s inevitable every \#country has got a \#vested \#interest, you \#can_t get away from that. and I \#think it_s just more bureaucracy isn_t it, rather than less.

13112 but \#there_s a conflict of \#interests there, and so the \#government \#can_t serve both. that_s \#right, they \#can_t \#fund the \#research through maf and then say well it_s not \#going \#to work lads.

30512 most people do \#go in there wanting \#to do what they perceive as \#right, but once they_re in there \#there_s always this \#idea of people wanting \#to hang on \#to \#power, \#to do this, \#to do that, I mean i \#think people are \#covering \#up a-lot-of \#things.

71712 he_s just \#going \#to be a \#scientist and he_s being \#paid you feel like the \#government the \#government could veto what he_s \#going \#to say. that_s \#right. and their \#funding, he_s not \#going \#to say anything, or she, are \#going \#to say anything that_s \#going \#to they_re very good, yes, I \#trust which.

74012 it_s just which \#way it \#goes, I \#think. yes. I just \#think it has \#to be \#regulated and monitored. very strictly. I don_t know, it_s \#really \#difficult \#to weigh \#up and \#balance.

17711 but if it \#comes my \#way and it_s \#to my advantage and my \#self \#interest I will \#go that \#way. \#self preservation. yes, but we can still say it_s \#wrong. so we want \#somebody \#else \#to make the \#decision \#really, and say you \#can_t do this. well we can still rely on the legitimacy of some sovereign authority saying, you know, but who that should be is a big point.

30711 \#right we_ll \#pay you 15 \#thousand pounds a \#year \#to do this \#job, ok, would he do it? well i \#think the \#answer would be no, so, you know, he_s, \#everyone has a \#certain, and i \#think very much most \#politicians have ambition, and if they have ambition they want \#to \#progress, they want \#to earn more money, they want \#to have more \#power,

$36711 \mathrm{Y}$ no. Y westminster council was quite \#interesting, they were accusing the \#person that did the \#commission, the auditor, of not being, of being \#biased, of being the prosecutor, detective and judge all at once,

17610 I don_t want \#to \#pay any tax but I recognise the \#right \#to \#pay tax because we have \#to \#fund \#certain \#things, in the same \#way you can recognise that, or we may recognise, \#believe it_s \#morally \#wrong \#to do a \#certain \#thing,

37410 and some of them will \#go almost \#to any lengths in order \#to get the \#results they desire. Y well they often disagree don_t they, and 
\#there_s, as you say about \#bse, they disagree about it, they don_t actually \#really know, they_re both, you know, you get both \#sides on the TV and I_m \#thinking well who do you \#believe, you know,

59710 there are \#areas which we at the \#moment, as we stand in 1996 technologically I don_t \#think we can appreciate what can \#happen and what will \#happen, that I_m sure. oh yes, I mean whatever, I mean \#man is expanding in its \#knowledge all the time and therefore whatever we do there are \#going \#to be \#bad \#sides and good \#sides from it, and the \#thing is,

60010 and all this \#knowledge has yet got \#to be sort of sought after, and it_s a \#question of \#regulation \#to decide whether we_re \#going the \#right \#way or the \#wrong \#way, and as I say, I hope we always \#go in the \#right \#way.

1449 \#to be honest \#there_s not an awful \#lot we can do for him OK but the \#guy that was \#shown but it was the \#research and lancet and so on, there is a \#drive and a recognition that \#doctors in the \#bma have a responsibility in \#terms of laying down standards in \#ethics, and lurching \#into the \#moral \#area.

1489 I \#think it_s a \#separate \#thing from within the \#profession what we are, where we_re \#going, and what is \#right and what is \#wrong, what is acceptable, \#professional, what is acceptable \#to the \#social morays of the time.

5039 and then \#somebody \#else says no that_s all \#wrong that, this is the \#real \#idea, and another hypothesis \#comes out, so you_re left with all these \#great bubbles floating in the \#air and you don_t \#really know which is the \#truth because \#nobodies actually said which is the \#real \#truth, which is the trouble with \#bse,

7169 yes. shady. shady and I_m \#definitely more inclined \#to \#pay them more attention if \#there_s a \#scientist working for the \#government he_s not \#going \#to have any, he_s not \#going \#to be working for the \#government is he,

3238 \#there_ll be something \#else. Y \#there_ll be something \#else, it_s \#coming back \#to this natural \#balance \#idea, \#scientists \#can_t explain. Y they \#can_t, no. Y no one can explain that. Y I \#think the \#general \#public tend \#to be portrayed as stupid and not capable of making \#decisions on facts that are given \#to them, or fly off at one tangent or another, and so the best \#way around that is not \#to give them the \#information,

5718 I don_t \#think it should \#go \#into the governmental body or the civil servant body, I don_t \#think they have the capability of understanding what is \#happening at that \#level, I \#think the \#scientific body in the \#world should regulate itself better \#to be able \#to police itself and \#to structure its own \#development,

\section{Open question responses}

Clé sélectionnée : A

527242284 horror \#film \#type \#things \#science \#fiction\$

852242255 it can \#go too far it_s good in some \#ways it_s \#messing

\#around with \#nature\$

587232408 I am \#worried about \#science \#messing \#around with human \#genes \#messing \#around with animal \#genes and \#taking \#things too far\$

24190430 \#science \#fiction \#films \#bad sides of it dabbling with

\#nature\$

583192404 mutants I do not \#agree with it at all we wouldn_t have had BSE if they hadn_t bloody \#well interfered no it_s just a \#feeling of \#interfering, you can_t \#alter \#nature without paying for it. \#nature always balances\$

682192051 \#interfering with the \#natural \#course of \#things\$

686192055 should \#let \#nature \#take its \#courses\$

775192148 should \#leave it \#alone \#reproduction identical

\#reproduction medically. \#taking one \#gene reproducing it \#trying it with foods $\$$ 
506182342 \#messing about too much should \#leave \#things \#alone \#trying to do all these tests growing plants in \#wrong colours should \#leave people \#alone not \#try to \#alter them\$

680182069 don_t \#agree with genetic engineering just \#feel \#things should be \#left as it is \#let \#nature \#takes its \#course can_t think of anything else\$

368170151 \#messing about with \#things which should be \#left \#alone nutcase will \#try to breed a \#super \#race get rid of \#things not up to scratch\$

699162048 I \#feel that sometimes it_s \#playing about with \#nature in a \#way that I don_t think is necessary it raises a whole pandora_s box of medical and \#ethical \#questions\$

84150544 \#messing \#around with \#nature\$

293150244 someone thinks they are \#god if someone is to have a \#child fine but to \#mess \#around is \#wrong\$

548152377 \#messing about with \#things they shouldn_t \#altering \#things they shouldn_t\$

643152032 they should \#leave \#well \#alone\$

728152079 \#interfering with \#nature too much not a good \#thing\$

404140103 \#reproduction and \#things like that \#tampering with

\#nature no, I_m not into all this\$

$49014056 \overline{5}$ in 200 \#years time will there be any human \#beings \#left or will we be \#changed completely\$

Clé sélectionnée : B

885412269 I don_t \#know \#really, \#that_s a tough one no I \#can_t \#answer that I_m afraid\$

920412336 I \#can_t \#really \#understand that one not \#sure what it \#means\$

455330097 not \#sure what it \#means never \#really \#heard anything about it\$

756332109 \#nothing don_t \#really \#understand what is \#meant by

this $\$$

103260523 it doesn_t \#really seem right \#nothing for the moment I \#can_t \#say I honestly \#understand it all\$

107250527 \#nothing don_t \#understand what you \#mean\$

184250088 \#nothing, I_ve never \#heard of the \#word\$

227250299 I_m so ignorant about it I \#can_t \#say anything. don_t

\#know $\$$

302250236 I don_t \#know \#really \#nothing\$

325250219 don_t \#know much about it \#can_t \#says

454250096 what you \#hear on TV \#that_s about it \#really\$

510252346 I don_t \#understand what it \#means \#really\$

217190334 I don_t \#really \#know much about this sort of thing so I

\#can_t \#really \#comment\$

52170501 well I don_t \#really \#know what you \#mean by it\$

87170547 it_s all wrong in my \#opinion \#nothing \#else\$

259170285 useful \#risky don_t \#really \#know much about it\$

492170567 not \#sure I_m too busy working don_t \#really \#understand\$

498170551 genes you \#know \#nothing \#else\$

22160428 don_t \#know \#nothing\$

Clé sélectionnée : C

698212047 it \#frightens me all the horrific changes we could do with it we could \#end \#up \#making little monsters there would be \#possibly, \#used correctly, enormous \#benefits but too many unscrupulous \#people could get there fingers in the pies

228190300 very \#dangerous \#subject they_re \#getting \#into. it will \#create more \#problems than it will solve $\$$

468180070 I don_t like \#genetic \#engineering I don_t \#want \#to \#end \#up with other \#peoples bits of body\$

57140506 \#they_ve \#made some amazing advances in \#different \#areas but \#there_s too much sensationalism and the media cashes in on it. I don_t know if we here the true version the time it \#gets \#to the public\$ 
154140397 I \#think there are \#moral \#issues. anything with \#genetic and technology manipulating is not \#right, it would \#cause \#problems between the church and the state\$

507142343 fascinating \#area would love \#to be involved host of \#different things wide \#area a-lot-of improvements can be \#made \#moral \#issues can be a \#problem they \#put a \#stopper on things\$

518142295 I_m fearful about it it_s in men_s \#hands. the \#use \#to which its \#put it could be a tool of the devil apprehension \#to do with altering the \#genetic \#make \#up in humans. it_s so broad\$

630142429 I don_t \#approve of \#genetically \#engineered \#soya \#beans being imported from the states \#want things labelled \#want \#to know what I am \#getting\$

640142009 it could be a good thing if \#used ethically you have \#to be very \#careful in whose \#hands it is, whose \#making the \#decisions about how it will be \#used and who they are \#making the \#decisions on behalf of things being equal which they aren_t I \#think it would be a good thing\$

815142221 things will go wrong with it which \#people haven_t \#thought of which could be pretty ghastly and it_s so complicated it_s \#difficult \#to get \#right first time. it could get \#into the wrong \#hands and be \#abused\$

312120226 I_d like \#to \#think they would \#use their knowledge for good and sensible \#causes but I wonder how-much we_re \#told\$

313120227 I \#think \#man has got \#to conserve and preserve with technology the skills he has been \#given. it has \#to be \#used properly, not \#abused. he can just as easily destroy as \#create\$

$69412 \quad 2043$ that \#used \#carefully they can be of \#great \#benefit but there is the \#issue of \#morals with regard \#to messing about the mother nature disrupting the earth_s balance\$

841122208 I \#think they are ruining our food it_s \#frightening, in the \#end they will manage \#to do what \#hitler failed \#to do\$

406110106 some \#form of \#genetic all about going \#into \#genetic of \#make \#up or boy or girl before \#birth\$

869112232 \#difficult \#to \#put \#into words without \#giving a-lot-of \#thought \#to it not a good thing terrible \#genetic \#engineering sounds like \#hitler all over again leave well alone\$

21490331 \#genetic \#engineering I_m not very \#happy about the \#necessity \#to do more research \#into cancer and son on I don_t \#think the woman who_s had $8 \mathrm{kids}$ is the correct way\$

21590332 I \#think that_ll \#make things \#worse \#to be honest\$

24690301 I don_t agree with \#genetic \#engineering on \#people it_s very \#difficult it_s all \#right if it works\$

Clé sélectionnée : D

2241050293 \#test \#tube \#babies \#artificial \#insemination \#cloning \#transplanting \#pigs \#organs into \#humans\$

157470400 ranges from \#cloning DNA and \#test \#tube \#babies\$

659472028 \#test \#tube \#babies \#transplants\$

80420489 makes a \#woman have a boy or \#girl if she wants it there could be production of \#babies by \#test \#tube \#creation it_s a-lot-of rubbish to have straight cucumbers vegetables have \#lost their taste\$

679392068 \#test \#tube \#babies issue about women on TV and \#sperm and father \#baby\$

750362103 \#test \#tube \#babies messing about with \#stuff you shouldn_t\$

$63 \overline{5} 0449$ they can \#manipulate chemistry of the \#human \#species\$

146350407 \#test \#tube \#babies\$

211350347 \#test \#tube \#babies\$

319350213 the lady having a \#baby from her \#dead husbands \#sperm\$

769352142 \#test \#tube \#babies\$

592292397 terminating a \#pregnancy if foetus has \#illness

\#selection \#artificial \#insemination\$

141250418 animal \#testing \#test \#tube \#babies\$

337250191 haven_t got a \#clue all \#human \#stuff don_t know\$ 
590252394 getting \#babies through \#test \#tubes\$

23240429 A \#woman who had eight \#babies\$

360240161 genes chromosomes \#manipulating them mutating them \#pigs

\#organs in \#humans genetically altered\$

636242005 I \#suppose it_s \#artificial fertilisation I_m thinking of

\#sperms from \#dead people etc\$

915242331 \#human \#babies\$

Clé sélectionnée : E

739282111 \#medical \#research \#new techniques for \#curing \#diseases

\#curing \#cancers \#mainly\$

927262323 \#fertility \#drugs \#solar \#energy it_s \#cheaper comes from sun \#computers they are clever and in education they will be used more genetic engineering will \#help people \#live longer i. e. \#cure \#diseases telecoms you can get in touch with all the \#world now space \#exploration \#earth is overcrowded. \#maybe we can go \#live elsewhere\$

17250422 \#companies like british biotec who \#develop \#new \#drugs for \#cancer\$

649252038 reduction of \#illnesses e. g. \#cancer \#general

\#improvement in \#health\$

774252147 IVF \#treatment \#medical \#research \#cures for \#diseases\$

959252475 \#general \#improvements in \#medicine more vaccinations and \#new \#cures\$

505210559 \#medicine \#cures for \#diseases 2341 \#mainly changes in \#medical \#research to \#help control \#diseases \#improvement in surgery transplant\$

377200142 it will \#help in \#finding \#cures for \#diseases\$

650202039 \#new food sources \#elimination of \#hereditary \#diseases

\#improved \#medical \#treatment avoidance of animal testing\$

139190416 pharmaceutical \#development. \#new \#cures \#eliminating \#disease like multiple dystrophy. genetic \#diseases even parkinson_s \#disease\$

298190232 I think of anything in the \#medical \#world \#research into \#finding \#cures for serious \#illnesses\$

345190199 scientific \#exploration \#medical \#exploration \#general search \#cure for \#cancer immunology\$

459190061 \#development of \#new \#drugs for control of \#cancer and arthritis and other \#diseases\$

537192385 \#basically in \#medicine \#research into \#cancer

\#technology environment will \#improve\$

620192438 supermarkets \#improve \#profitability \#prevent \#hereditary \#disease\$

715192085 the \#development of \#new \#drugs \#helping the injured \#new methods to \#aid them\$

968192485 enhance our \#lives \#improve \#living conditions \#maybe \#help the sick and poor\$

114160516 A good thing because it will \#help \#improve mankind and \#help get \#over the present difficulties will \#help with \#cancer \#research and mental \#illnesses these are the only two I can think of\$

476160058 applications to genes to \#medical \#technology genome project genetic \#medicine as a whole \#new \#drugs \#new \#treatments\$

Clé sélectionnée : F

164300388 \#changing things like \#fruit. making it \#resistant to \#pests, then you don_t have to use \#chemical sprays it makes \#fruit and \#vegetables have a \#longer \#shelf \#life\$

720282071 \#chemicals and the \#effect on the \#environment \#farm \#animals\$

783272136 \#changing the \#food we \#eat \#biological and zoological things on the good \#side, they can get \#rid of a-lot-of \#inherited diseases\$

357220177 cattle livestock feed \#improving the \#productivity of \#animals CAT policy more efficiency cut \#down on \#waste more \#industry planning\$ 
509222345 \#using \#chemicals in \#food \#production and \#farming \#advancements in medical science

591222396 radiated \#foods to \#keep \#longer \#shelf \#life\$

162190385 creating a \#longer \#shelf \#life for \#fruit and \#vegetables stopping the need for \#crop spraying \#larger \#fruit and \#vegetables\$

21170427 analyse the \#body \#food \#environment\$

480170042 \#pest \#resistance \#crops eradication of \#food \#crops genetic \#insulation of \#food \#crops for making \#insulin\$

676172065 genetic engineering \#improving \#quality of \#food in agricultural \#sense rather than factory \#farming\$

828172214 \#fruit and \#veg \#tomatoes tomato puree\$

150160393 \#heart transplants from \#animals disfigurements can have \#ears \#grown\$

401160120 DNA fingerprints revolutionising crime \#detection adding new genes to \#plants radio activity on \#fruit for killing \#bacteria killing \#pests in \#crops\$

584152405 improved \#farming cheaper \#food sterile \#environments. as in not germs as such but \#animals which are disease free, but have no \#resistance to germs etc. I think we_ll go \#down the \#same path\$

833132219 things to do with the \#vegetable kingdom \#food and cloth textiles \#growing \#tomatoes in fluid rather than earth trying to \#grow \#food in \#space or those \#sort of conditions\$

396120113 human fertilisation and its \#effects \#fruit and \#veg that we \#eat\$

$127 \quad 110364$ \#chemicals \#plants\$

208110344 \#sort of genetic engineering no \#sort of \#using \#animals to help pollution in an \#environmental friendly way \#bacteria to break \#down things\$

222110340 \#growing \#ears on mice\$

\section{News media}

Clé sélectionnée : A

16182 in 1992, the first \#babies were \#born after \#specific \#testing for \#cystic \#fibrosis. since then, there has been \#screening for about six different very \#serious genetic \#diseases, and \#babies have been \#born \#to \#couples who have \#previously had a \#child \#die from an \#inherited \#disorder.

39856 we should be very circumspect in the use of that \#power. lord \#winston_s \#unit already \#offers \#pre \#implantation \#diagnosis of \#embryos \#to \#couples \#carrying the gene for \#cystic \#fibrosis, a \#life \#threatening \#disease of the \#lungs and digestive system.

16549 one patient at \#risk has \#seen five \#young \#woman in her \#family \#suffer \#breast \#cancer; she herself has had both \#breasts \#removed prophylactically \#to try \#to forestall the \#disease.

16648 she wants \#to have her \#embryos \#screened rather than have her \#children \#suffer the \#anxieties she \#experiences. such \#screening which is closely monitored by the human \#fertilisation and \#embryology \#authority would not only \#avoid this, but would also \#prevent this \#cancer in \#future generations.

32848 however successful the trial may be, PPL_s sheep have a secure \#future in providing AAT \#to \#treat another \#lung \#disease, \#hereditary emphysema a \#fatal \#disorder \#causing \#lung \#damage \#similar \#to that \#resulting from \#cystic \#fibrosis.

53046 and the \#termination of one or more \#foetus is necessary \#to \#ensure the wellbeing of the other, s. the \#case \#reported two \#weeks ago was the first time in britain that a \#twin had been aborted for \#social \#reasons because the \#mother \#felt that she would be \#unable \#to \#cope A \#similar \#case was \#reported tuesday, 
39044 \#woman having in vitro \#fertilisation \#treatment may \#soon be able \#to \#screen out \#embryos \#carrying the genes that cause \#breast \#cancer, \#to \#reduce the \#risk of their \#children developing the \#disease.

40344 \#woman will not be \#willing \#to subject themselves \#to \#ivf and all that \#involves, unless there is a very, very \#strong \#reason \#to think that they are \#seriously at \#risk of an \#inherited \#disease.

54044 what has genetic \#testing got \#to do with all this? \#medicine_s ability \#to diagnose \#diseases prenatally is advancing by leaps and bounds: already genetic \#testing can identify \#foetus \#suffering from \#conditions such as \#cystic \#fibrosis or \#muscular \#dystrophy.

51742 the widespread anguish about the incineration of unwanted \#embryos or the \#abortion of a \#twin merely confirms them in their fundamental \#faith that we are reaping the \#moral \#disaster that sixties permissiveness sowed.

36441 the \#certainty which \#people \#seek in \#science is, of \#course, an illusion. on many of the issues that \#worry \#people \#today there is no \#scientific consensus. claims that \#synthetic chemicals \#contribute \#to declining \#sperm \#levels are \#strongly contested. \#scientific estimates of the \#risks of global warming \#vary \#widely.

71241 the \#certainty which \#people \#seek in \#science is, of \#course, an illusion. on many of the issues that \#worry \#people \#today there is no \#scientific consensus. claims that \#synthetic chemicals \#contribute \#to declining \#sperm \#levels are \#strongly contested. \#scientific estimates of the \#risks of global warming \#vary \#widely.

15939 this technique was first used in 1990, when cells were \#removed after \#ivf \#to \#test for the \#sex of the \#embryo. this was \#to \#help \#couples who might have a \#baby which, if male, could \#suffer a \#sex \#linked \#disorder such as duchenne \#muscular \#dystrophy.

17239 it is unthinkable that we could \#screen a single \#embryonic cell for more than a sole gene trait in the foreseeable \#future. even analysis of one gene \#defects \#usually poses problems. for example, it is true that we can now \#screen an \#embryonic cell for the \#specific gene \#causing \#muscular \#dystrophy, rather than just \#testing for \#sex.

17739 in a pluralistic \#society it is \#reasonable \#to \#allow \#individuals \#to take \#decisions which \#affect only them and their \#families. spurious arguments about practising \#eugenics, about slippery slopes, and about \#designer \#babies, are a poor \#reason \#to \#prevent work doing much \#to promote \#healthy \#life.

15236 they are \#short of \#stature and have a variety of other \#symptoms, \#usually a webbed, broad neck, a low hairline on the neck and drooping eyelids. there is a \#failure \#to develop reproductive organs. \#somatropin, without \#affecting many of the \#signs of \#turner_s, adds an inch or two \#to \#height.

17036 nature sheds most \#turner_s \#embryos during the first ten \#weeks. \#doctors like me are \#accused of wanting \#to make \#designer \#babies. it is \#frequently said that while \#embryo \#testing may be \#reasonable \#to \#prevent \#serious \#birth \#defects, we are on a slipperly slope.

39436 there is a \#strong \#case for \#screening these \#people. \#inherited \#breast \#cancer often does not \#strike until a \#woman is in her forties or fifties and can sometimes be successfully \#treated.

52936 in what \#sense was the recent \#abortion of a \#twin a watershed? so called_selective \#termination or_selective reduction of \#foetus in the \#womb has been \#carried out before, but only when \#multiple \#embryos \#implanted during \#ivf \#treatment have all taken,

Clé sélectionnée : B

43350 SEVERAL \#genetic \#modified \#food preceded \#soya on to \#british \#supermarket \#shelves. the \#co op \#sells its own brand \#vegetarian \#cheese that is \#manufactured by using a \#genetic \#modified \#enzyme \#called chymosin. 
14047 yet as \#things stand, we won_t \#know whether the \#food we are \#eating \#contains \#oil or \#flour from the \#new \#soya \#bean, \#developed by the chemical \#company \#monsanto with a \#gene from a \#bacterium that \#makes it \#resistant to the \#firm_s own \#roundup \#herbicide.

11943 GENETIC \#altered \#food sounds like the \#stuff of science fiction, but the truth is it_s already in our \#shops. at the \#co op you can \#buy \#cheese produced using \#gene \#technology and at \#safeway or \#sainsbury youll find \#genetic \#modified \#tomato \#paste, all \#clearly \#labelled as such.

72943 the \#warning comes as the first \#american \#harvest of \#genetic \#manipulated \#soya superbeans is about to \#arrive in \#britain. two \#thirds of \#items on \#supermarket \#shelves \#including \#breads, pastries, vegetable \#oils, ice cream, chocolate, \#margarine, cereals and \#processed meat \#products \#contain \#soya.

73042 by december, 60 per cent of \#processed \#food could \#contain \#oil or \#flour from \#genetic \#manipulated \#soya \#plants. dr \#john \#fagan, a professor of \#molecular \#biology from fairfield, iowa, \#said the mechanisms \#used for \#genetic \#manipulation of \#foodstuffs are inherently risky,

42740 the \#beans produced will not be \#sold as \#beans, but in a \#processed \#form as \#flour or \#oil. derek burke, chairman of the \#advisory \#committee on \#novel \#food and processes, which has given \#clearance to the \#new \#products, \#says that \#processing means no trace of the \#gene, or the \#enzyme it produces, is present in the \#final \#product.

73340 they soon \#cross pollinate or reproduce with their \#natural counterparts and the \#genetic \#manipulation can spread throughout the species. the \#new \#soya \#plants, bred by the chemical \#company \#monsanto, have had a \#gene \#introduced from a \#bacterium that \#makes the \#bean \#resistant to \#monsanto_s \#roundup \#herbicide.

13339 \#current regulations \#say the \#plant \#material \#requires environmental risk \#clearance; vetting of the \#foodstuffs themselves is not compulsory. zeneca, the \#british \#company which \#developed and produces the \#genetic \#modified \#tomato \#used in the \#paste \#sold by \#sainsbury and \#safeway, \#says 900, 000 cans have been \#sold so far in the UK.

1035 but people who were \#allergic to \#brazil \#nuts were \#allergic to the \#soya \#beans. we have been \#forced to \#accept that we won_t be able to \#label them \#separately, \#said a spokeswoman for \#sainsbury_s which last february \#issued a customer leaflet with a \#genetic \#engineered \#tomato \#products that \#said:

42234 they \#include \#breads, pastries, vegetable \#oil, salad dressings, \#margarine, sweets, cereals, some drinks and meat \#products, and chocolate. geraldine schofield of the \#food and drink federation \#says that two \#thirds of \#items on \#supermarket \#shelves \#contain \#soya \#products.

42434 it will be \#harvested next month and on the \#world \#market by \#october. the \#new \#plants, produced by \#monsanto, \#contain an \#introduced \#gene from a \#bacterium which \#makes them \#resistant to the \#herbicide glyphosate, \#sold in various \#forms to farmers and \#gardeners and best \#known as the weedkiller \#roundup.

43934 no \#genetic \#engineered \#crops are yet \#grown \#commercially in \#britain, but \#food \#products already \#cleared for \#use here \#include \#oil from four different \#types of transgenic oilseed \#rape.

1433 the \#beans all go into the same \#processing \#plants, it \#said, so that the \#genetic \#modified \#beans are distributed throughout the \#final \#product, such as \#soya \#oils and \#flours.

27633 the \#new \#soya \#bean, \#developed by the Us \#company \#monsanto, is being \#harvested in the US this year and \#contains a \#gene which \#makes it \#resistant to a \#herbicide.

22632 the \#argument is not over the \#use of \#processed \#maize in human or animal \#food, since \#processing destroys the \#genes at the centre of the \#issue. but the european \#position, if maintained, would 
prevent the \#importation of unprocessed \#maize, and the \#sale of the \#genetic \#modified \#seed for \#planting in europe.

44032 sometimes \#genetic \#engineering has unexpected and unwelcome results. when a \#seed \#company \#genetic \#modified \#soya \#beans by \#introducing a \#brazil \#nut protein to \#improve the \#beans \#quality as animal feed, it was found that people who were \#allergic to \#brazil \#nuts were also \#allergic to the \#new \#soya \#bean.

1231 the result is that it could be \#virtually \#impossible to feed the family without \#buying something \#made with the \#altered \#soya \#beans, which have been \#engineered by the chemicals group \#monsanto to be \#resistant to a \#herbicide \#called \#roundup also \#made by \#monsanto.

42131 the \#shops want \#labels \#saying it has been \#modified, while the \#manufacturers \#say this is impracticable and could be misleading. potentially, a \#huge \#range of \#products could \#contain small amounts of \#soya \#flour or \#oil produced from \#genetic \#modified \#plants.

73431 farmers who \#grow the \#manipulated \#crop can \#use larger amounts of \#roundup to kill \#weeds, \#making the \#growing of \#soya \#beans cheaper and \#easier. but, dr \#fagan argued, the \#use of the \#genetic \#manipulated \#soya \#bean could encourage a \#roundup \#resistant \#strain of \#super \#weed.

Clé sélectionnée : C

109104 he said in a lecture to the \#soil \#association in london. \#prince \#charles, who has \#farmed organically on his highgrove estate in gloucestershire for 11 \#years, advocated fundamental \#reform of the \#european \#union_s \#common \#agriculture \#policy so \#farmers everywhere would be eligible for government \#grants in \#return for committing all their \#land to environment \#friendly \#farming and high \#animal \#welfare standards.

81191 we could do \#nothing. we could \#continue \#polluting our food and \#paying the \#price in sickness and \#unnecessary health \#bills. or we could admit that \#intensive \#farming has abused \#nature beyond endurance and now it is time to swap \#mad cows for ones that are merely \#wild.

27188 he is \#expected to \#continue the \#campaign in brussels next \#month by attending a symposium of leading \#european \#union agriculturists and \#environmentalists to \#discuss the \#reform of the \#common \#agriculture \#policy.

27275 he will \#lobby there for more \#sustainable \#agriculture \#policies. the \#prince first \#highlighted his \#concern over \#modern \#farming \#methods when he \#addressed a conference of the royal agri cultural \#college in cirencester, gloucestershire, 13 \#years ago.

27375 he provoked controversy by saying that many \#modern production \#methods are not only wasteful but probably \#unnecessary. the \#prince_s tenants who \#farm duchy of \#cornwall \#land are \#encouraged to be \#environmentally \#friendly, but are \#free to \#adopt their own \#farming \#methods.

10571 bovine spongiform encephal opathy, \#bse, could \#come to be seen as \#nature_s revenge for mankind \#violating her \#laws, the \#prince of \#wales told \#organic \#farmers \#last \#night.

68271 THE \#prince of \#wales \#last \#night delivered a passionate criticism of 50 \#years of \#industrial \#farming, which has produced \#bse, the \#destruction of the \#ancient countryside and horrifying abuses of \#animal \#welfare.

10166 sir: I wonder if \#prince \#charles, \#bse is an \#offence against \#god, says \#prince \#charles, 20 \#september, \#considers his beloved \#jack russell to be an \#offence against \#god.

11365 much of his \#speech castigated 50 \#years of industrialised \#farming, dwelling on the heavy damage done to landscapes and wildlife and the hidden \#costs of \#agriculture air, \#soil and \#water \#pollution, but \#giving equal \#weight to \#animal \#welfare.

69558 he said there was no \#point in blaming \#farmers for the \#price signals that the \#common \#agriculture \#policy \#gave which said we wanted \#cheap food and plenty of it. 
11855 and other research has suggested a \#significant \#decline in the \#trace mineral content of our fruit and \#vegetables over the \#last 50 \#years. the \#ministry of \#agriculture \#gave britain_s \#small number of \#organic \#farmers the lowest incentives in \#europe, he said.

26255 THE \#prince of \#wales is \#preparing to relaunch himself as an \#environmental and social \#campaigner in his first \#significant \#speech since his \#divorce. he will \#warn later this \#month of the growing \#dangers of genetic engineered food and \#modern \#farming \#techniques.

37755 amongst the many \#factors contributing to the \#bse \#crisis the \#feeding of an herbivorous species with \#animal protein rendered from the \#same species \#stands out starkly. there can be few clearer expressions of the \#modern \#view of the earth as a resource to be \#exploited for the \#benefit of humans.

72555 amongst the many \#factors contributing to the \#bse \#crisis the \#feeding of an herbivorous species with \#animal protein rendered from the \#same species \#stands out starkly. there can be few clearer expressions of the \#modern \#view of the earth as a resource to be \#exploited for the \#benefit of humans.

80955 and \#organic \#farmers do not qualify for many of the \#european \#union subsidies that are heaped on conventional \#farmers. francis blake of the \#soil \#association admits: at the moment conventional

\#agriculture is so heavily supported that \#organics just cannot compete. 68951 \#bse was just one \#example of how society, and \#farmers, had been \#paying twice for \#cheap food. the disease would have \#cost taxpayers pounds 1. 4 \#billion in slaughter \#bills by the end of the \#year and \#farmers much suffering. \#farming would also \#cost the \#public pounds 1 \#billion, the \#cost of removing \#pesticides from the \#water \# supply.

9947 but suzanne moore seems to begrudge him the latter, \#charles: king of the legumes, \#september 20. what could be more relevant to the present day than to \#point out that \#modern \#farming \#methods have led to \#bse and to the \#exploitation of \#farm \#animals and livestock, such as battery \#chickens?

11047 \#feeding cattle with protein derived from cattle or other \#farm \#animals, which almost certainly caused the \#bse outbreak, was _totally inappropriate. perhaps \#bse will \#come to be seen as one \#example. of how \#nature \#hits back when we \#violate her \#laws.

69647 they had been outstandingly successful in achieving those goals. the polls showed that the \#public \#prized the countryside \#second after \#free \#speech. yet, while \#green \#farming in all forms not just \#organic was \#top of the \#public_s demand from the CAP, only one arable acre in 100 was eligible for \#environmentally sensitive area \#payments.

Clé sélectionnée : D

57430 on the \#face of it, the idea is as implausible as jenner_s, but like his it \#seems to \#work. \#dr douglas lowrie and \#colleagues from the \#national \#institute for \#medical \#research im mill hill have \#shown that \#mice can be \#protected against TB by \#injecting them with a \#vaccine made from \#naked \#dna.

5121 she blames the subsequent \#break \#up of her marriage to a soldier on the army_s reluctance to \#send him abroad with a sick \#wife. she has undergone about 100 \#blood transfusions and 34 \#operations to \#keep her \#going. \#brown, who is now virtually housebound, said she would also welcome a \#pig \#kidney.

44720 a neat two page \#paper that finally \#showed how the miniaturisation could \#take \#place. \#each \#dna \#molecule was \#shaped like a \#long \#twisted \#ladder the famous double helix \#shape.

45420 other \#ladder chunks \#built chemicals that registered what was \#going on in the \#cell, and forced the signpost regions to \#work faster or \#slower as needed. the great \#molecule could even fix itself. certain \#stretches carried the blueprints for \#repair \#vessels that were \#sent gliding \#out to fix \#rungs that had been \#broken by incoming cosmic rays, or \#ordinary \#body heat. 
56620 if only one of the pair of genes has the \#flaw, the \#cells have the \#surface \#protein and \#hiv can \#infect them, but the \#progression is much \#slower.

25218 \#scientists are \#creating a new source of \#drugs from potatoes. they are genetic engineering the vegetable to \#turn it \#into an edible \#vaccine against \#killer diseases. their next \#target is the banana. the \#researchers have altered the genetic make \#up of \#potato plants to \#produce a \#cholera \#vaccine that has already been \#shown to \#work on \#laboratory \#mice.

48717 \#professor \#james is heading a \#trial at the rowett \#research \#institute \#into sibutramine, which \#fights hunger by boosting the levels of \#serotonin and noradrenaline in the \#brain.

56317 now, further genetic tests on two of the 15 have \#found they have a \#flaw in a \#matched pair of genes, \#leading to \#cells in their \#immune \#system \#lacking a \#particular \#surface \#protein which \#hiv \#normally uses to \#infect the \#cells.

29315 if lord blandings was still at blandings castle he would feel that his opinion of \#pigs was vindicated. \#old fashioned \#pigs the \#large \#whites so revered by lord blandings but so despised by modern butchers are the \#breed chosen by \#research \#scientists in \#cambridge for \#transplant \#experiments.

29615 the \#cambridge \#research \#workers have successfully \#transplanted the genetic modified \#swines \#kidneys \#into primates, and have \#shown that the \#monkeys did not develop a resultant hyperacute \#rejectionary reaction,

65715 the \#team has \#found a set of genetic \#instructions which can be \#put \#into cancer \#cells \#created in the \#laboratory, \#turning the \#cells \#into a kind of \#vaccine.

3914 this means their organs and those of their offspring should signal to a recipient_s \#immune \#system they are \#human. last year \#wallwork and \#white \#announced that \#pig \#hearts had \#kept \#going in \#monkey recipients for \#up to eight weeks in \#trials.

6114 when \#broken \#up fragments of \#dna from a \#blood \#sample come \#into contact with it, they pair off with any \#matching \#dna. material that does not pair \#up is washed away.

55614 when \#normal \#mice were \#shown \#pups, the \#fosb \#protein was switched on in the preoptic \#area. with the \#knockout \#mice, that could not and did not happen.

64514 \#hiv is a retrovirus: it cannot replicate unless it can smuggle itself \#into an \#immune \#system \#cell and hijack the \#victim_s \#dna to do its \#work for it.

66014 the \#finding \#shows that we can induce a successful \#immune \#response against \#brain \#tumours and that we can apparently \#cure pre \#existing \#tumours in some of our animals, said \#dr john sampson, who \#led the \#research,

$841 \quad 14$ the film stars sir richard attenborough as scottish entrepreneur \#hammond who \#builds a \#dinosaur theme \#park on an \#island. billionaire \#hammond has ploughed money \#into \#research which has \#led to \#scientists being \#able to \#extract \#blood from \#mosquitoes frozen in fossilised \#tree sap 65 million years ago.

81513 \#scientists are hoping to re \#create a woolly \#mammoth, the \#giant prehistoric \#creature which \#became extinct 10, 000 years ago. using \#jurassic \#park techniques, they will \#take \#dna \#extracted from fossilised remains in a bid to bring the beast back to life.

18312 \#scientists have \#discovered the \#mutant gene \#largely responsible for causing the most common form of \#skin cancer, basal \#cell carcinoma. the US \#team, which \#published its \#findings in the \#journal nature genetics say the gene, called patched, must mutate before \#cells can \#start to \#become cancerous. 